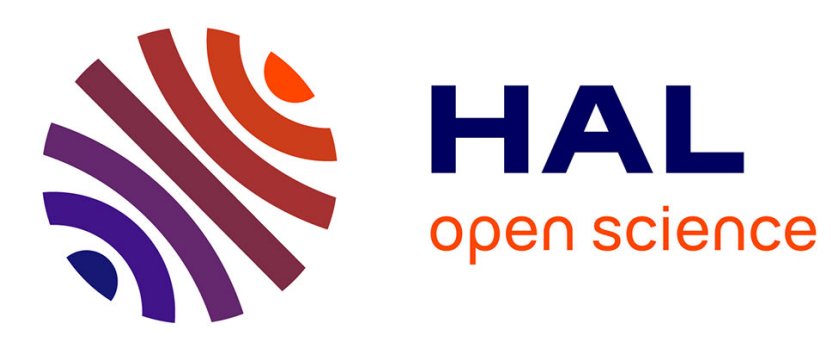

\title{
Lost in (Clinical) Translation: Recent Advances in Heparin Neutralization and Monitoring
}

Benjamin Ourri, Laurent Vial

\section{To cite this version:}

Benjamin Ourri, Laurent Vial. Lost in (Clinical) Translation: Recent Advances in Heparin Neutralization and Monitoring. ACS Chemical Biology, 2019, 14 (12), pp.2512-2526. 10.1021/acschembio.9b00772 . hal-02995798

\section{HAL Id: hal-02995798 \\ https://hal.science/hal-02995798}

Submitted on 4 Dec 2020

HAL is a multi-disciplinary open access archive for the deposit and dissemination of scientific research documents, whether they are published or not. The documents may come from teaching and research institutions in France or abroad, or from public or private research centers.
L'archive ouverte pluridisciplinaire HAL, est destinée au dépôt et à la diffusion de documents scientifiques de niveau recherche, publiés ou non, émanant des établissements d'enseignement et de recherche français ou étrangers, des laboratoires publics ou privés. 


\section{Lost in (Clinical) Translation: Recent Advances in Heparin Neutralization and Monitoring}

Authors: Benjamin Ourri and Laurent Vial*

Affiliation: Univ. Lyon, Univ. Claude Bernard Lyon 1, ICBMS UMR CNRS 5246, 43 Boulevard du 11 Novembre 1918, 69622 Villeurbanne Cedex, France

*To whom correspondence should be addressed: laurent.vial@univ-lyon1.fr

Abstract: The heparin family, which includes unfractionated heparin, low-molecular heparin and fondaparinux, is a class of drugs clinically used as intravenous blood thinner. To date, issues related to both to the reversal of anticoagulation and the blood level determination of the anticoagulant at the point-of-care remain: while the only U.S. Food and Drug Administration (FDA) approved antidote for heparin displays serious efficacy and safety drawbacks, the current assays for heparin monitoring are indirect measurements subject to their own limitations and variations. Herein, we provide an update on the numerous recent chemical approaches to tackle these issues, from which it is clear that some new antidotes and sensors for heparin certainly have the potential to exceed current clinical standards. This review aims to review a field that requires close collaborations between physicians, biologists

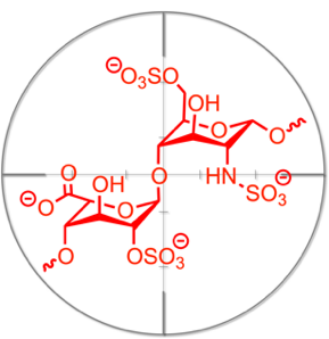
and chemists in order to foster advances toward clinical translation.

\section{Context and challenges}

Heparin, which belongs to the family of glycosaminoglycans (GAGs), is a linear sulfated polysaccharide and consists of repeating disaccharide subunits of $\alpha-1,4$ linked uronic acid and D-glucosamine (Figure 1). As a consequence, heparin displays the highest density of negative charges among biomacromolecules. This polyanion is widely used as an intravenous anticoagulant due to its ability to accelerate the rate at which antithrombin (AT) inhibits serine proteases within the blood coagulation cascade, most notably factor Xa and thrombin. ${ }^{1-4}$ Polymers of various lengths such as unfractionated heparin (UFH, $\mathrm{M}_{\mathrm{w}} \sim 15 \mathrm{kDa}$ ), low-molecular-weight heparins (LMWHs, $\mathrm{M}_{\mathrm{w}}=3.6-6.5 \mathrm{kDa}$ ), and the synthetic pentasaccharide fondaparinux $\left(\mathrm{M}_{\mathrm{w}}=1.7 \mathrm{kDa}\right)$ are routinely delivered to patients. While UFH is used during acute thrombotic events or to maintain blood fluidity during procedures requiring extracorporeal circulation (i.e., cardio-pulmonary bypass or hemodialysis), ${ }^{5,6}$ LMWHs and fondaparinux are prescribed to treat and/or prevent deep vein thrombosis and pulmonary embolism. ${ }^{7}{ }^{8}$ With an estimated one billion doses of heparin produced every year, heparin's market is rapidly growing, driven by the ageing of populations and the increasing incidence of cardiovascular diseases. ${ }^{9}$
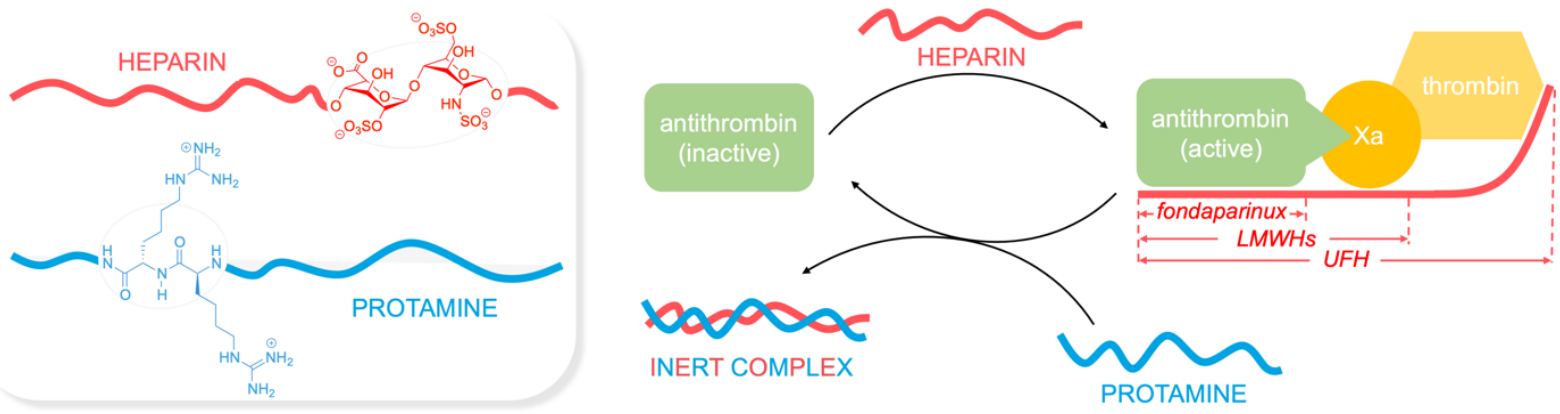

Figure 1. Schematic representation i) of the anticoagulant heparin and its antidote protamine (left), and ii) illustrating the inactivation of factor Xa and thrombin by AT (right).

The antidote for heparin is protamine, a small arginine-rich protein $\left(\mathrm{M}_{\mathrm{w}}=5 \mathrm{kDa}\right)$ which restores - with varying degrees of success - a normal coagulation cascade by forming inert non-covalent complexes with the anticoagulant (Figures 1 ). ${ }^{10}$ Whereas protamine fully neutralize the effect of UFH after cardiac bypass surgery in more than 2,000,000 patients/year, ${ }^{l l}$ the antidote only partially restore coagulation (with maximal efficiency of $c a .60 \%$ ) in case of accidental overdose or massive bleeding caused by LMWHs. ${ }^{12}$ Finally, protamine is inactive toward fondaparinux, and the management of its hemorrhagic complications is primarily supportive. ${ }^{13}$ Apart from its limited efficacy, there are other concerns about the therapeutic use of protamine since it: i) involves medical risks with an incidence of adverse, sometimes fatal reactions varying from $0.06 \%$ to $10.7 \%$, including anaphylaxis and systemic hypertension ${ }^{14}$ iii) is extracted from fished salmon milt, its production being therefore limited by the livestock availability and carrying a risk of contamination. For instance, the radioactive pollution in Fukushima resulted in a worldwide supply shortage of protamine in $2012,{ }^{15}$ and iv) has no FDA-approved surrogate is therefore included in the list of essential medicines by the World Health Organization. ${ }^{16}$ Together, these concerns raised the incentive for researchers to find alternative synthetic, broad spectrum, and nontoxic heparin reversal agents.

In addition, quantifying heparin in patients' blood or plasma - which is required in order to prevent complications (e.g., hemorrhaging) and to optimizing protamine doses, mainly relies on clotting time-based assays such as active partial thromboplastin time (aPTT) and anti-factor Xa assay. ${ }^{17-19}$ The aPTT is the time required for the formation of a stable clot from the addition of a platelet substitute, factor XII activator, and $\mathrm{CaCl}_{2}$ in citrated plasma. On the other hand, the anti-factor Xa assay measures the activity of heparin by measuring the ability of heparin-bound AT to inhibit a single enzyme, factor Xa. 
These tests are additionally affected by many unrelated factors such as hypothermia or inflammation for aPTT, ${ }^{18,20}$ and pregnancy, end stage renal disease, postthrombolysis, or bilirubin levels for the anti-factor Xa assay. ${ }^{21}$ Once again, these limitations raised the incentive for researchers to find alternatives to the ubiquitous aPTT and anti-factor Xa assay, which must provide the overall amount of heparin in the tested fluids (ideally blood), be robust, fast, and easy to implement in clinical settings. In addition, these methods cannot be implemented at points-of-care and fail to accurately determine the overall amount of heparin present in body fluids.

Herein, we provide the readers with a concise overview of the recent advances in heparin binding and sensing, starting from late 2013 as a follow-up to the review of Bromfield et al. ${ }^{22}$

\section{Heparin neutralization}

Three classes of objects were described during the last five years to achieve this goal: proteinic/peptidic/pseudo-peptidic, dendritic/polymeric, and self-assembled binders (Fig. 2).

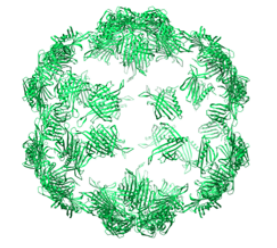

Virus-like particles

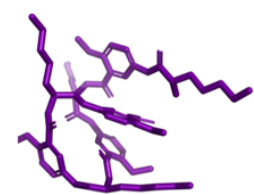

(Pseudo)-peptides

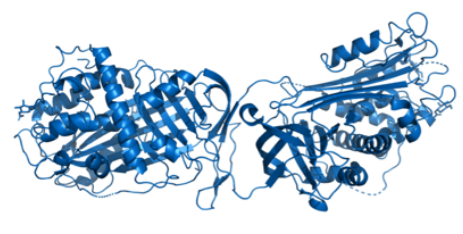

Proteins

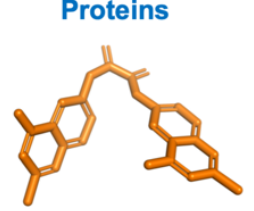

Small molecules
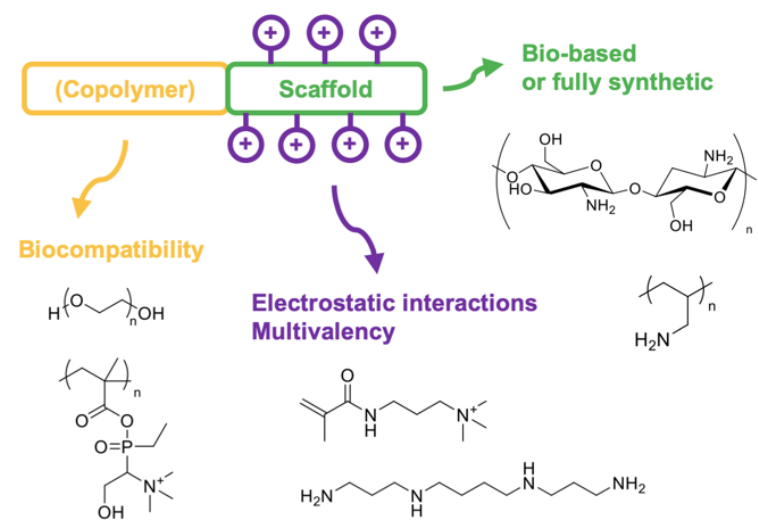

Electrostatic interactions Multivalency
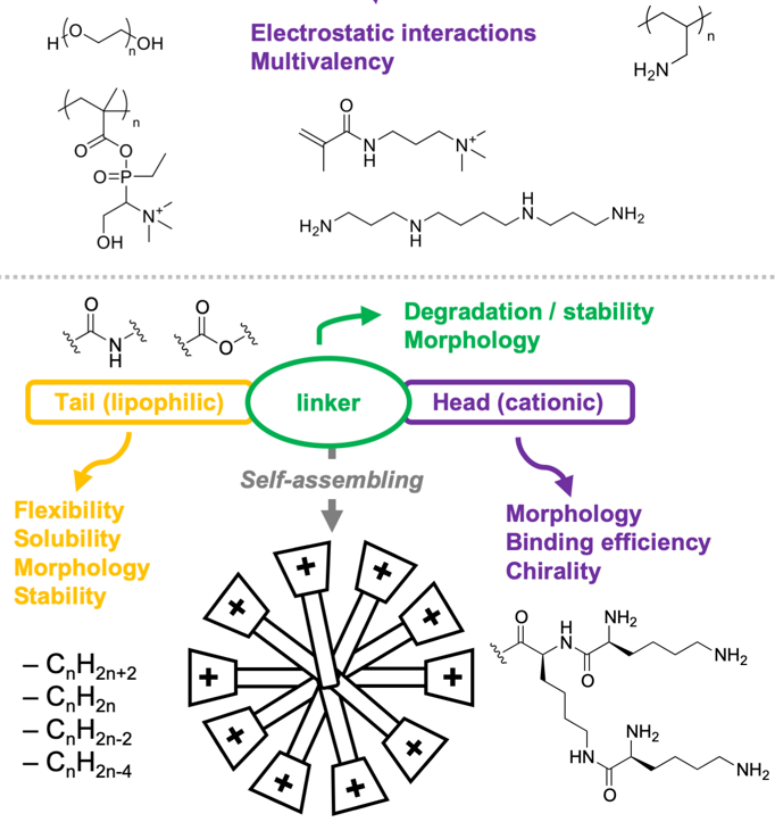

Figure 2. Recent approaches toward heparin neutralization involving bio-inspired binders (upper left), linear polymers (upper right), dendritic polymers (lower left), and self-assembled micelles (lower right). When heparin binders are schematically represented, selected examples of the molecular structure of their components as well as their respective properties are displayed.

\section{Proteic/peptidic/pseudo-peptidic binders}

Numerous natural proteins are known to bind heparin. ${ }^{23}$ Some of these proteins and their inactivated variants have been considered as potential heparin antidotes. Two modified AT, recombinant-inactivated (ri-AT) and chemically inactivated (chiAT), were proved to reverse the anticoagulant activity of UFH, LMWH, and fondaparinux in plasma in a global coagulation assay (i.e., thrombin generation assay). ${ }^{24}$ Since chi-AT displayed residual anticoagulant properties counteracting its performance as an antidote, only ri-AT was selected for a cardiopulmonary bypass study on murine model. ${ }^{25}$ In this latter study, the efficiency and half-time of UFH neutralization proved to be higher than with protamine, without the side effects on hemodynamic parameters and plasma histamine levels generally observed with the FDA-approved antidote. Obviously, further preclinical studies are required to assess the immunogenicity, pharmacokinetics and safety of the inactivated protein. Yet, this study certainly provides incentives to further assess the ability of other inactivated proteins involved in the coagulation cascade to neutralize heparin. Native (unmodified) proteins, which are not involved in the coagulation cascade can also be considered. Histones, which are highly basic proteins around which DNA wraps up within the cell nuclei are known to bind to heparinoids, were thus investigated as protamine analogues through aPTT tests in plasma. ${ }^{26}$ The anticoagulating activity induced by therapeutic doses of heparin required low concentrations of histones to be inhibited by $50 \%\left(\mathrm{IC}_{50}=1.8 \mathrm{and} 6.6 \mu \mathrm{g} / \mathrm{mL}\right.$ for the neutralization of 0.2 and $0.6 \mathrm{IU} / \mathrm{mL} \mathrm{UFH}$, respectively). It can of course be argued that a protein involved in inflammation and infection pathway may have a poor specificity and trigger substantial side-effects. Engineering of proteins that are not known 
as heparin binders has also been investigated. A single amino acid mutation on a bacteriophage Q $\beta$ virus-like particle yielded a large cationic region that was replicated 180 times over the capsid (Fig. 2). ${ }^{27}$ APPT assays revealed that complete neutralization of $1.3 \mu \mathrm{g} / \mathrm{mL}$ heparin required $1 \mathrm{mg} / \mathrm{mL}$ of particle, while protamine started to display aberrant behavior starting from $0.07 \mathrm{mg} / \mathrm{mL}$ with increased coagulation times.

Compared to proteins, peptides have a higher activity per unit mass, are less immunogenic, and their manufacturing costs is lower (synthesis for small peptides vs. recombinant engineering for proteins). Since numerous proteins are known to bind heparin via their arginine- and lysine-rich regions, using peptides derived from these regions may be an attractive approach toward reversal agents. For instance, the Semaphorin3A protein is known to bind to GAGs by its C-terminal region. Two Cterminus-derived basic peptides bound UFH with affinities in the low micromolar range, but their ability to restore clotting has not been investigated so far. ${ }^{28}$ Short peptides can be directly derived or inspired by protamine, whose arginine content is $67 \%$. Protamine mimics consisting of 3 to 20 arginine residues were prepared by Dou et al., ${ }^{29}$ who found that a minimum of eight arginine residues was required to observe anti-UFH activities. The (Arg) $)_{15}$-based peptide was then compared to protamine in vivo on rats. aPTT and anti-factor Xa assays showed that both compounds neutralized UFH similarly, but - at the opposite to protamine - the mimic exhibited no immunogenicity in guinea pigs. However, the alkaline nature of both antidotes caused increased histamine release with rapid infusion.

Therefore, moving from peptidic backbones to pseudo-peptides in order to avoid these side effects also encountered with protamine was proposed. One of the main attractive features of pseudo-peptides is their low susceptibility to proteolytic degradation in vivo. For instance, PER977 is a small synthetic di-arginine piperazine, designed to target heparin through electrostatic interactions and hydrogen bonding. The literature concerning PER977 displays contradictory results: some authors claimed that this species does not bind to LMWH, ${ }^{30}$ while others demonstrated that PER977 neutralizes LMWH efficiently. ${ }^{31}$ Although the pharmacodynamics of the pseudo-peptide is not understood, its side-effects are very limited. ${ }^{31,32}$ While PER977 does not exhibit any secondary structure, one could also envision pseudo-peptides adopting precise conformations. In this context, De Grado et al. reported peptide-like foldamers, made of $L$-lysine and a salicylic acid derivative (5-amino-2methoxybenzoic acid, Sal), that were explicitly designed to form two-stranded $\beta$-sheet-like structures in which the basic lysine side chains project from one face of the structure in order to bind to fondaparinux. ${ }^{33}$ Remarkably, the tetrameric foldamer $\mathrm{H}_{2} \mathrm{~N}-$ (Lys-Sal) $)_{4}-\mathrm{CONH}_{2}$ self-assembled into hexameric aggregate upon association with the pentasaccharide, and was able to inhibit its anti-factor Xa activity in an aqueous buffer $\left(\mathrm{EC}_{50}=3,6 \mu \mathrm{M}\right)$. The foldamer was also active versus UFH in human plasma $\left(\mathrm{IC}_{50}=1,1 \mu \mathrm{M}\right.$ for the neutralization of $0.5 \mathrm{U} / \mathrm{mL}$ from aPTT assay). In order to further simplify the drug candidates, small organic molecules that display the typical features of short peptides were also prepared. Bis-2-methyl-4-amino-quinolyl-6carbamide, also known as surfen, and its derivatives carry both cationic charges (to mimic the side chain of Lys or Arg) and CONH-based motifs (to mimic the peptidic bond). In particular, oxalyl surfen was shown to neutralize UFH, the LMWH enoxaparin, and fondaparinux in vitro ( $\mathrm{IC}_{50}$ in the $\mu \mathrm{M}$ range for the neutralization of $0.2 \mathrm{IU} / \mathrm{mL}$ ) and in vivo in mice (Fig. 2). ${ }^{34}$ It was suggested that surfen molecules could align along the oligosaccharides in a cooperative manner, and block the formation of the AT-heparin complexes.

\section{Polymeric/dendritic binders}

Polymers, which can either be bio-based or fully synthetic, are high molecular weight molecules composed of repeated building blocks. Some of these building blocks can carry cationic functions at physiological $\mathrm{pH}$, hence exposing a large positively charged molecular surface to heparin. In all cases, the choice of the polymer's backbone is of crucial importance since functionalizing distinct materials with the same moieties does not yield identical reversal activity against heparin. For instance, the glycidyl-trimethylammonium (GTMAC) chloride motif was grafted onto various bio-based polymers including dextran (Dex), $\gamma$-cyclodextrin (GCD), or pullulan (Pul). ${ }^{35,}{ }^{36}$ Polymers Dex-GTMAC, Pul-GTMAC and GCD-GTMAC had a similar degree of functionalization but contrasted UFH binding abilities, and the mass ratio of polymer to UFH required to bind $90 \%$ of UFH in aqueous buffer was 2.7, 1.9 and superior to 8, respectively. The degree of functionalization also plays a significant role since a minimum of $c a$. 25 positive charges on Dex-GTMAC were required to start observing UFH binding in solution. The most substituted Dex-GTMAC bearing $c a .260$ cationic motifs turned out to be the most potent antidote to UFH (similar to protamine), fully restoring the parameters of the thrombosis development and typical measures of the coagulation cascade (i.e., aPTT and anti-factor Xa activity) in rats and mice. Neutralization abilities of this candidate for protamine replacement was neither reported on LMWH nor on fondaparinux. Yet, its biocompatibility is undoubtedly superior to protamine as it did not induce any immune response, was normotensive and hemodynamically neutral in model animals. In addition, the polymer was rapidly eliminated (half-life of $12.5 \pm 3.0$ minutes) without any blood and organ toxicity. ${ }^{37}$ The polymeric backbone of antidotes can also be fully synthetic, such as in PAH (poly(allylamine hydrochloride)). Directly inspired by protamine, a PAH polymer on which $9 \%$ of the amino groups were replaced by arginine was tested as heparin antagonist. ${ }^{38}$ In vitro experiments in bovine blood serum revealed that, compared to protamine sulfate, the dose of PAH-ARG required for a complete reversal of aPTT was cut by half. The reversal ability of this polymer was further confirmed in vivo on a rat model. Surprisingly, cytotoxicity studies indicated that PAH-ARG polymer has considerably lower cytotoxicity than PAH, which contrasts with the general statement that arginine-rich peptides like protamine interact more strongly with lipidic bilayers than lysine-rich peptides. ${ }^{39}$ Arginine-rich peptides are consequently toxic to cells from concentrations around $800 \mathrm{nM}$ to $50 \mu \mathrm{M}$ while lysinebearing polymers are only cytotoxic at higher concentrations $(>50 \mu \mathrm{M}){ }^{40}$ Since a strong-density of positive charge along the polymeric chains often leads to increased toxicity, a well-known strategy toward its reduction consists in copolymerizing it with nontoxic copolymer blocks such polyethylene glycol (PEG) chains (Fig. 2). ${ }^{41}$ Among other examples, ${ }^{42}$ a copolymer made of PEG and poly(3-methacraloylamino)propyl trimethylammonium chloride (PMAPTAC) displayed total fibroblast cell viability up to $150 \mu \mathrm{g} / \mathrm{mL}$, while the corresponding non-PEGylated analogue was found to be strongly toxic (viability $<50 \%$ ) at concentrations above $50 \mu \mathrm{g} / \mathrm{mL} .{ }^{43}$ The candidate restored coagulation and completely reversed both clotting time and antifactor Xa activity caused by UFH, the LMWH enoxaparin or fondaparinux in Wistar rats. In addition, the copolymer did not modify the cardiorespiratory parameters of the animals, nor it damaged or significantly accumulated in their kidneys and liver. 
Contrary to linear (co)polymers, dendrimers are three-dimensional objects that benefit from their higher flexibility for heparin binding. In fact, when the core of polycationic poly(amidoamine) dendrimers (PAMAMs) was modified with a polyphenylenevinylene motif, therefore rigidifying the whole structure, it turned out that their relative ability of binding UFH per cationic charge in a buffered aqueous medium dropped in comparison with unmodified PAMAMs. It demonstrated that the overall flexibility of dendrimers allows them to adapt their global shape more easily to maximize the total number and efficiency of contacts between the partners. ${ }^{44}$ Also, a very large number of positive charges borne by the dendritic polymers is not prerequisite to achieve efficient binding of heparin. Five generations of dendrigrafts of poly- $L$-lysine (DGLs), which displayed from 8 to 727 charged nitrogen atoms, were benchmarked for heparin binding in an aqueous buffer using a simple dyedisplacement assay. ${ }^{45}$ It turned out that the second generation DGL - exhibiting only 41 positive charges - already archived optimum binding, suggesting that additional positive surface failed to contact heparin. Anti-factor Xa assays with this secondgeneration dendrigraft showed $100 \%, 90 \%$, and $60 \%$ neutralization in human plasma of UFH, enoxaparin, and fondaparinux, respectively. In addition, higher generations of DGLs had intrinsic anticoagulant activity. Coagulation is a complex system with parallel positive and inhibitory feedback loops resulting from interactions between the endothelium, plasma proteins, and platelets. According to the literature, one may hypothesize that large cationic dendritic structures may disrupt key platelet functions. ${ }^{46}$ As mentioned before, the introduction of PEG chains and is an effective strategy to limit antidotes' drawbacks. A dendritic candidate reported by Kizhakkedathu et al. was named UHRA, standing for universal heparin reversal agent. Its design is based on a hyperbranched polyglycerol scaffold bearing 20 trivalent ammonium motifs as heparin binding groups, capped with short PEG chains as protective shell against non-specific interactions (Fig. 2) ${ }^{47}$ Remarkably, the antidote was not only able to fully neutralize UFH and LMWHs, but also $90 \%$ of the anticoagulant activity of fondaparinux in human plasma. This superior reversal activity of UHRA observed in vitro could be effectively translated in vivo, where the dendritic polymer completely and rapidly neutralized the activity of both UFH and LMWH enoxaparin, whereas protamine was only effective in neutralizing UFH but could reverse only $60 \%$ enoxaparin activity in rats. Non-specific binding to plasma proteins is believed to be responsible to the adverse effects seen with protamine. UHRA has minimal influence on blood proteins, clotting, or clot morphology, when protamine bound to the fibrin clot, which could explain how the protein initiates clot lysis and increases bleeding after surgery..$^{48}$ Insights into the role of the PEG chains was provided by the authors. ${ }^{49}$ Isothermal titration calorimetry (ITC) experiments revealing that the enthalpic contribution to UFH binding was higher for UHRA in comparison with protamine, which could be related to its higher number of positive charge (60 vs. 22). However, an entropic penalty was observed for the dendritic polymer in comparison with the protein, which was due to the compression of the PEG chains upon interaction with UFH. This entropic penalty was the price to pay for the eradication of non-specific interactions with anionic blood components. The dendritic polymer lacking its PEG chains induced the aggregation of blood components, which was as for protamine - at the origin its intrinsic anticoagulant property. It was also found that UHRA activity originated from the efficient disruption of the AT-UFH complex in the coagulation cascade. Such an understanding of the mechanism and the driven forces behind the binding event between the anticoagulant and its antidote is necessary for future optimization and clinical development.

\section{Self-assembled binders}

Self-assembling is the spontaneous and reversible organization of multiple simple building blocks into a single complex superstructure. Among self-assembled superstructures, micelles are formed by the aggregation of surfactant molecules, which are made of a hydrophobic tail, a linker, and a polar head. Aggregates that bear cationic polar heads present a large positively charged and organized surface to heparin. Over the last quinquennium, Bromfield et al. developed a new family of selfassembled multivalent micelles (SAMul) toward heparin binding (Fig. 2) ${ }^{50}$ Each part of the building blocks plays a key role in both the self-assembling process and the subsequent heparin binding event. Even though the aliphatic tails are buried inside the micelles, their nature has a major influence on the micellar properties. A too long aliphatic chain disfavored solubility, yielding large and uncontrolled aggregates that should be avoided. ${ }^{51}$ In addition, excessive lipophilicity led to disaggregation over time upon binding to plasma proteins such as albumin. ${ }^{52}$ Preventing rigidity in the design of the tail was also recommended since the packed surfactants were destabilized as the degree of unsaturation increased. ${ }^{53}$ For a $\mathrm{C}_{18}$ chain containing from 1 to 3 double bonds, critical micelle concentration increased from 42 to $78 \mu \mathrm{M}$ in aqueous buffer, while the cation/anion charge excess at which $50 \%$ of a dye is displaced from the anticoagulant's surface $\left(\mathrm{CE}_{50}\right)$ for UFH increased from 0.80 to 2.30 in the same medium. The linkages between the tails and the heads of the building locks were mostly amide and esters bonds. Because esters could undergo hydrolysis over time, they avoided the accumulation of SAMul in excess (i.e., unbind to heparin), which is highly desirable in order to avoid side-effects. Free micelles fell out over a 24 hours timescale in physiological conditions, while micelles interacting with heparin seemed to be protected from degradation. ${ }^{52}$ The last part of the surfactant is the head, which also controlled the morphology of the self-assemblies. First- and second-generation dendrons of lysine yielded wormlike micelles and spherical micelles, respectively. ${ }^{53}$ The worm-like assembly was better shape-matched to heparin and displayed a slightly better capacity to bind UFH from a simple dye-displacement assay in human serum $\left(\mathrm{CE}_{50} \approx 1 v s\right.$. $\mathrm{CE}_{50} \approx 25$ for the spherical micelles). In addition, the worm-like assembly seemed to protect the lipophilic part of the micelle to be disrupted by interactions with proteins like albumin. Surprisingly, increasing the net charge of the head did not lead to improved affinities for heparin since electrostatic repulsion between the building blocks destabilized the micelles. ${ }^{54,55}$ The nature of the cationic motif also played a part. Two heads bearing an identical positive net charge of 2, N,N-di-(3-aminopropyl)-N-methylamine and spermidine, exhibited distinctive binding efficacy $\left(\mathrm{CE}_{50}=0.69\right.$ vs. 0.34 in aqueous buffer, respectively). Finally, introducing chirality in the head could also improve the affinity toward UFH. For instance, a variation with two successive chiral alanine and lysine residues showed that the self-assembly of SAMul was more stable with the LL/DD rather than DL/LD sequence, which was translated into $\mathrm{EC}_{50}$ values (120 to $140 \mu \mathrm{M}$ range in aqueous buffer, respectively). ${ }^{56}$ 


\section{Heparin monitoring}

Chemical sensors contain two basic functional components: a receptor and a transducer, which makes use of a physical change accompanying the reaction for the detection and quantification of the analyte (Figure 3). We decided to categorize these approaches according to the receptors' backbone: (poly-)peptidic binders, (metallo-)organic binders, polymeric binders, and nanoparticle binders. Table 1 gathers the results obtained since late 2013.

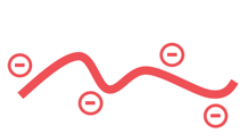

HEPARIN

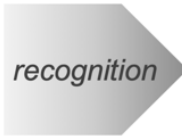

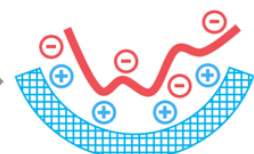

BINDER

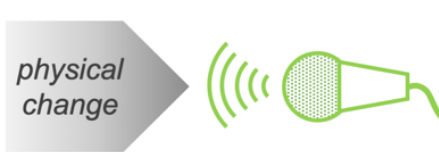

TRANSDUCER

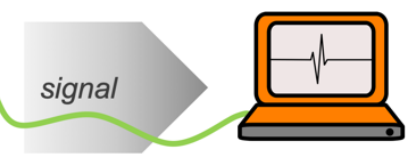

USER INTERFACE

Figure 3. A schematic representation of a sensor for heparin.

\section{(Poly-)peptidic binders}

It was a natural to select AT, the heparin proteic binder within the coagulation cascade, as a recognition unit for the design of chemical sensors. When cationic micelles and fluorescent quantum dots (QDs) modified with AT are added into UFH samples, the aggregation of QDs-UFH complexes on the micelles was monitored by spectral imaging fluorescence microscopy. ${ }^{57}$ Using this sensing ensemble, the recovery of the spiked heparin at $0.00465 \mathrm{U} / \mathrm{mL}(\sim 5 \mathrm{nM})$ in $0.1 \%$ human plasma was acceptable. Other native proteins such as collagen, which is the most abundant extracellular matrix protein and known to bind many circulating biomolecules including GAGs, were associated with nanoparticles (NP) toward heparin monitoring. From an integrated scaffold made of collagen fibrils and negatively charged citrate-capped gold NPs, localized surface plasmon resonance signals (LSPR) from a competition assay could be exploited for the detection of 5 to $100 \mu \mathrm{M}$ UFH in an aqueous medium. ${ }^{58}$

Arginine- and/or lysine-rich linear peptides (i.e., protamine or protamine mimics) as receptors also were an obvious choice toward heparin sensors. Regarding the transducer part, which makes use of a physical change accompanying the reaction for the detection and quantification of the analyte, six strategies have been explored so far:

- Excimer fluorescence emission that resulted from the multiple binding to heparin of peptides bearing a pyrene moiety. Not surprisingly, longer peptides (net charge of +4 ) led to the ratiometric detection of UFH concentrations in diluted serum samples that were one order of magnitude lower than those reached with shorter peptides (net charge of +2 ). ${ }^{59,} 60$ Oversulfated chondroitin sulfate (OSCS) was reported to be the principal contaminant in UFH, which is a non-natural highly sulfated synthetic GAG, which may lead to severe adverse reactions, such as angiodema, hypotension, swelling of the larynx, and even death. ${ }^{61}$ By adding an heparinase, which digestive activity is selectively inhibited by OCSC, into solutions of contaminated UFH and a pyrene-appended peptide, Lee et al. were able to detect as low as $0.0001 \%$ (w/w) of OSCS contamination by monitoring the decrease of fluorescent change due to undigested heparin. ${ }^{62}$ However, the optical response to GAGs was dependent on the concentration of these previous chemosensors since GAGs mainly consist of disaccharide repeating units. This drawback was circumvented by linking two pyrene labeled heparin-binding peptides using a glycine-rich (i.e., hydrophobic) spacer. ${ }^{63}$ Such a finely tuned probe displayed monomer emission at $376 \mathrm{~nm}$ with relatively weak excimer emission in serum due to its binding to the hydrophobic sites of serum albumin. A significant increase in excimer emission at $480 \mathrm{~nm}$ and a concomitant decrease in monomer emission was observed upon heparin addition. Because excimer formation is an intramolecular event in this case, the optical response turned out to be independent of the concentration of the chemosensor, with a limit of detection (LOD) that was less than $1 \mathrm{nM}$ in $5 \%$ serum solutions. Such a LOD is well below the therapeutic levels of heparin used during cardiovascular surgery (i.e, 17-67 $\mu \mathrm{M}$ or 2-8 $\mathrm{U} / \mathrm{mL}$ ) and postoperative and long-term care (i.e., $1.7-10 \mu \mathrm{M}$ or or $1.7-10 \mathrm{U} / \mathrm{mL}$ ).

- Aggregation-induced emission (AIE) that resulted from the binding to heparin of peptides bearing a tetraphenylethene (TPE) moiety. A short peptidyl probe (net charge of +3 ) displayed both the ability i) to form aggregates with UFH, therefore allowing its monitoring in diluted serum samples (LOD of $2.6 \mathrm{nM}$ ), but also ii) to inhibit the heparinase-mediated digestion of heparin, therefore allowing the detection of OCSC contamination in the samples (vide supra) ${ }^{64}$ In general, generic cationic peptides showed limited specificity for heparin against other GAGs. In this context, a probe including a peptide (sequence: RKRLQVQLSIRT) from the G domain of the laminin $\alpha 1$ chain - known for high-binding affinity and specificity toward heparin - allowed heparin detection without interference from biological abundant anions, biomolecules, as well as GAGs such as chondroitin sulfate $(\mathrm{ChS})$ and hyaluronic acid (HA) ${ }^{65}$ At that point, it must be noted that the mean concentration of endogenous total GAGs in serum is about $15 \mathrm{nM}$, which is about two orders of magnitude below heparin therapeutic concentrations, thus greatly limiting their possible interferences during the monitoring of the exogenous anticoagulant. ${ }^{66}$ Whereas single emission sensors tend to be affected by a variety of factors (i.e., instruments, environmental conditions, and sensor concentration), dual-channel fluorescent sensors provide internal calibration through dual-channel output toward increased sensibility and reliability. For instance, protamine induced the aggregation of both an AIE motif (TPE) and an aggregation-caused quenching motif (phloxine B) immobilized at the surface of a fibrous strip. ${ }^{67}$ UFH disrupted the aggregate, switching the TPE and phloxine B fluorescence off and on, respectively. The fibrous mats turned from cyan to green and bright yellow under ultraviolet illumination in the presence of corresponding heparin concentrations of 0.4 and $0.8 \mathrm{U} / \mathrm{mL}$. 
- Surface-enhanced Raman scattering (SERS) that resulted from the aggregation of anionic gold NPs in presence of protamine or protamine mimics. ${ }^{68,69}$ The authors exploited the correlated de-aggregation of the NPs and decreased of the corresponding SERS signal in presence of UFH toward its detection in diluted serum samples. One of the advantages of Raman reporters is their resistance to photo-bleaching owing to the short lifetime of Raman virtual energy states.

- Fluorescence resonance energy transfer (FRET) that resulted from the electrostatic adsorption of gold NPs on $\mathrm{NaYF}_{4}: \mathrm{Yb}_{3} \mathrm{Er}_{\mathrm{H}}$ NPs or silicon QDs. ${ }^{70,71}$ Anionic gold NPs interacted with protamine and then desorbed from the surface of $\mathrm{NaYF}_{4}: \mathrm{Yb}, \mathrm{Er}$ NPs or silicon QDs, resulting in the recovery of the fluorescence. Upon addition of UFH, the FRET ensemble reformed owing to the stronger association between heparin and protamine. Whereas the sensing of UFH with these sensors could only be achieved in diluted serum samples, lanthanide-based NPs generated visible emission with low-energy near-infrared excitation (i.e., $980 \mathrm{~nm}$ versus $360 \mathrm{~mm}$ for silicon QDs) that should eliminate autofluorescence from biological macromolecules.

- Colorimetry that resulted from the inhibition by UFH of the oxidase-like activity of protamine-modified platinum NPs. ${ }^{72}$ Although the optical signal decreased with increasing concentrations of heparin (i.e., turn-off sensing), it was possible to discriminate concentrations of heparin ranging 0 and $20 \mu \mathrm{M}$ in plasma samples simply by naked eye.

- Electrochemical signal that resulted after the controlled release of protamine from a membrane electrode, allowing the monitoring of UFH in undiluted sheep blood at concentrations ranging from 0 to $40 \mathrm{U} / \mathrm{mL} .{ }^{73}$ In addition, the electrode could be regenerated via current-driven ion fluxes of protamine, which allowed on-line measurements of heparin in a flow injection mode. A similar static strategy involved protamine adsorbed on the silicon oxide surface of a microcapillary impedimetric sensor. ${ }^{74}$ Heparin binding resulted in surface charge alteration that could be monitored by measuring the device impedance in buffer.

Using a highly negatively charged biomolecule such as DNA for heparin monitoring may seem counter-intuitive at first glance. Nevertheless, UFH was able to disrupt a complex made from $\mathrm{Tb}^{3+}$, guanine-rich ssDNA, and the above-mentioned heparinspecific peptide from laminin $\alpha 1$, leading to the restauration of the lanthanide photoluminescent signal in a simple buffer ${ }^{75}$ Similarly, UFH also disrupted complexes made from adenosine-rich DNA architectures (double strand or G-quadruplex) and coralyne, which is an aromatic dye whose fluorescent signal is enhanced when it remains separate from water in the hydrophobic environment of the genetic material. ${ }^{76-78}$ Although such coralyne-DNA ensembles are turn-off sensors, they offer short response times $(<10 \mathrm{~min})$ as well as LODs for heparin in the low-nanomolar range in diluted serum samples. Turn-on sensing was achieved by using a DNA molecular beacon consisting of a 22-mer loop and a stem of a pair of 12-mer adenosine bases functionalized with a fluorescent reporter at the 5 '-end and a quencher at the 3 '-end. ${ }^{79,80}$ The presence of coralyne (or cardiotoxin 3, a venom polypeptide from Taiwan cobra) promoted these adenosine-adenosine mismatches to form stable adenosine-coralyne-adenosine (or adenosine-cardiotoxin 3-adenosine) complexes in the stem, leading to the Förster resonance energy transfer (FRET) quenching of the fluorescent signal that resulted from the conformational change of the strand from a random-coil to hairpin structure. This time, disrupting the complexes upon UFH addition led to the destabilization of the hairpin structure and to the restoration of the fluorescent signal in plasma. Another example of FRET sensing involved amino-capped carbon QDs and a fluorescein-labelled ssDNA that formed fluorophore-quench pairs. UFH competitively bound to C-QDs and restored the green fluorescent signal. ${ }^{81}$ This method was used to recover $96.9-106.6 \%$ of heparin in rabbit serum samples.

\section{(Metallo-)organic binders}

The solubility of (metallo-)organic architectures is lower than that of biomolecules in aqueous media. Whereas the low working concentration range needed for the detection of heparin may sometimes prevent their precipitation, the hydrophobic character of the probes could also lead to non-specific binding to numerous proteins in blood. For instance, a mixture of buffer and acetone was required to observe the formation of a poly(pseudorotaxane)-type complex between UFH and organoplatinum(II) metallacycles made of a pyridine-type ligand bearing TPE units. ${ }^{82}$ The presence of an aggregation-induced emission (AIE) active TPE motifs allowed the detection of the anticoagulant in the relevant $0-28 \mu \mathrm{M}$ concentration range. Introducing watersolubilizing ammonium groups on TPE derivatives has made it possible to work in aqueous medium, and the nearly quantitative recovery of UFH detection in $1 \%$ human serum samples has been achieved. ${ }^{83}$ The role of the hydrophobic/hydrophilic balance has been investigated during the heparin-induced aggregation of oligo(p-phenylenevinylene)-based bis-pyridinium bearing alkyl chains of various lengths (i.e., $-\mathrm{C}_{6} \mathrm{H}_{13},-\mathrm{C}_{10} \mathrm{H}_{21}$ and $-\mathrm{C}_{12} \mathrm{H}_{25}$ ) ${ }^{84}$ The compounds with longer alkyl chain formed aggregates that were relatively less stable in water (i.e., precipitated after 12-14 hours), and the addition of UFH to the less hydrophobic probe resulted in a gradual increase $(\mathrm{LOD}=\sim 12.5 \mathrm{ng} / \mathrm{mL})$ of the aggregated-induced emission in diluted fetal bovine serum (FBS). However, the saturation concentration of heparin was found to be $c a .3$ times higher in comparison with measurements in a buffered solution, suggesting an association of the probe inside the hydrophobic cavity of the serum albumin. It was also possible to exploit the hydrophobicity of the probes to produce micelles, where pyrene units are buried into the self-assemblies, and linear polyamine units offer a large cationic surface. ${ }^{85} \mathrm{~A}$ large increase in excimer emission intensity was observed upon heparin binding in a competitive aqueous medium (i.e., $10 \mathrm{mM}$ Tris $\mathrm{HCl}$ buffer with $150 \mathrm{mM} \mathrm{NaCl}$ ), which was associated with the reinforcement of micelle self-assembly. Because these SAMul nanostructures could also interact with the hydrophobic domains of proteins such as albumin, they were disrupted by $12.5 \%$ serum.

Heparin probes should not only avoid interference binding with blood components, but also overcome the autofluorescence of biological samples. This latter requirement can be fulfilled by emission wavelengths that are above $600 \mathrm{~nm}$. For instance, a fluorescent sensor made of a tetraphenyl imidazole group, as AIE fluorophore, and a benzothiazolium group, as anion binder, displayed red emission $(650 \mathrm{~nm})$ upon heparin-induced aggregation. Using this probe, the measured recoveries of UFH in $10 \%$ diluted human serum samples ranged from $96 \%$ to $105 \%$ with less than $5 \%$ relative standard deviation. ${ }^{86}$ A dicationic push (donor)-pull (acceptor) system containing a diethylaminocoumarin and a pyridinium group connected by a $\pi$-spacer displayed red emission at $665 \mathrm{~nm}$ from intramolecular charge transfer. ${ }^{87}$ Contrary to other GAGs (e.g., ChS, HA), UFH acted as an 
efficient quencher for the emission of the dication, allowing its detection in FBS solutions at nanomolar concentrations (14.8 $\mathrm{nM}$ to $148 \mathrm{nM}$ ). This selectivity may be explained by the higher number of negative charges borne by UFH (-4 per major disaccharide unit) in comparison to $\mathrm{ChS}$ (-2 per major disaccharide unit) or HA (-1 per major disaccharide unit). In order to target GAGs with lower negative charge densities than UFH, Krämer et al. used a polyamine-functionalized perylene diimide probe that displayed a higher number of positive charges (net charge +8 ). The quenching of red-light emission upon aggregation allowed the detection of both UFH and the LMWH enoxaparin with quantification range of about $0-5 \mu \mathrm{g} / \mathrm{mL}$ for both analytes. ${ }^{88}$ Although the last two probes displayed long emission wavelengths, they are turn-off sensors. The advantage of a fluorescence turn-on over a turn-off mechanism is that it requires a specific binding event to create a new signal, whereas fluorescence quenching can occur in multiple ways. Fluorescent turn-on detection could also be achieved via more exotic sensing mechanisms, such as the displacement of a quenched cationic dye from the cavity of a polycationic pillar[5]arene macrocycle,${ }^{89}$ the displacement of the quenched fluorescent surfen from the surface of few-layer graphene oxide, ${ }^{90}$ or the torsional relaxation hindrance of a cationic fluorogenic ultrafast molecular rotor, ${ }^{91}$ which led upon UFH binding to the restoration of UV absorbance or fluorescence signals.

Apart from optical absorbance and emission, the formation of sound waves following light absorption in a material sample known as photoacoustic effect was also exploited toward heparin monitoring. Jokerst et al. found that the photoaccoustic signal of the methylene blue dye dramatically increased with increasing concentrations of both UFH and the LMWH enoxaparin in a dose-dependent manner. ${ }^{92}$ Clinically relevant heparin concentrations could be detected in blood in 32 seconds with a detection limit of $0.28 \mathrm{U} / \mathrm{mL}$. Finally, a bis-quaternized perylene dye acted as a bridge between two citrate-capped silver NPs, creating a SERS effect that could be turned-off upon addition of UFH in diluted bovine serum. ${ }^{93}$ This sensing ensemble displayed an exceptionally large linear range of detection from $0.1 \mathrm{ng} / \mathrm{mL}$ to $10 \mu \mathrm{g} / \mathrm{mL}$, and a very low LOD of $0.08 \mathrm{ng} / \mathrm{mL}$. In addition, the excitation wavelength was $785 \mathrm{~nm}$, therefore preventing any biological interferences.

\section{Polymeric binders}

Chitosan is a bio-sourced polysaccharide that could be seen as the cationic equivalent of heparin, and it was therefore used as recognition unit in chemosensors in association with anionic gold-silver NPs displaying SERS properties for signal transduction. ${ }^{94}$ Upon an initial addition of UFH, the nanoparticles began to aggregate, resulting in the increase of the Raman signal, whilst the aggregates began to disassemble after reaching a critical concentration of heparin, resulting in the decrease of the Raman signal, This is one of the rare example of sequential on/off signalization that permitted the monitoring of heparin over a wide range of concentrations (i.e., 50 to $800 \mathrm{ng} / \mathrm{mL}$ ).

On the other hand, the use of fully synthetic polymers allows the combination of various components, some dedicated to recognition and others to signaling, in order to access sophisticated heparin detection strategies. Cationic polyfluorenes are known light-harvesting antenna that amplifies the emission of phosphorescent transition-metal complexes based on FRET. In this context, the binding of UFH to an alternate co-polymer made of $92 \%$ of a cationic fluorene and $8 \%$ of a phosphorescent iridium complex block allowed its ratiometric sensing in buffered water by virtue of the modulation of FRET efficiency. ${ }^{95}$ Cationic fluorene units have also been exploited in polymers in combination with cationic TPE units. ${ }^{96}$ Such a polymer encoding yielded dual-channel sensors for UFH since the fluorescence of TPE units increases while the one of fluorene units decreases upon aggregation. But once again, the study was only conducted in a simple buffer medium. The optical reporter could also be disconnected from the polymeric recognition unit. For instance, the appearance of a significant excimer emission was observed upon the aggregation of a benzoperylene dye onto a poly(diallyldimethylammonium) chloride (PolyDADMAC) polymer via electrostatic, hydrophobic, and $\pi-\pi$ stacking interactions. ${ }^{97}$ UFH was able to disrupt the aggregates, therefore releasing the free dye, and the excimeric to monomeric optical transition signal was exploited toward the ratiometric detection of the anticoagulant in diluted serum samples. Another linear polymer, polybrene, that was sometimes used to reverse heparin anticoagulation before being supplanted by protamine, was able to increase the phosphorescence of Mn-doped ZnS QDs. ${ }^{98}$ The phosphorescence signal was quenched upon the displacement of polybrene from the nanoparticle's surface by UFH, allowing the detection of UFH in diluted human serum samples with an appreciable linear range of concentrations $(0.05-1.4 \mathrm{U} / \mathrm{mL})$. Branched polymers have also been envisioned for heparin monitoring. A polycationic DGL was able to bind multiple polyanionic fluorescent peptides, leading to the self-quenching of the optical signal that could be restored upon UFH addition in a typical indicator-displacement assay. ${ }^{99}$ This sensing ensemble allowed the detection of the anticoagulant in human blood at clinically relevant levels. In the same conditions, a linear poly- $L$-lysine was not able to bind the probe, therefore highlighting the importance of the dendritic topology for a strong association event (vide supra). In addition, depending on the loading of the probe on the dendrigraft, various GAGs induced an increase or a decrease of the fluorescent signal as they displaced the probes from the polymer or they compacted the probes on the polymer's surface, respectively. ${ }^{100}$ This unique feature allowed the blind identification of five different GAGs by linear discrimination analysis. As mentioned before, ratiometric and dual channel detections have clear advantages over single emission sensors. Luo et al. went further with a tri-channel sensor for UFH using a cationic branched polyethylenediimide (PEI) polymer and the phloxine B, a dye that displays colorimetry, fluorescence and resonance Rayleigh scattering (RRS) that were weakened in the phloxine B/PEI complex. ${ }^{101}$ Free Phloxine B was gradually released upon UFH addition, causing the enhancement of the RRS, fluorescence, and absorption signals that can be exploited for sensing experiments in 50\% human serum (linear ranges were $0.08-0.4 \mathrm{U}_{\mathrm{mL}} \mathrm{mL}^{-1}$ for RRS, $0.08-0.5 \mathrm{U} \cdot \mathrm{mL}^{-1}$ for fluorescence, and $0.2-0.5 \mathrm{U} \cdot \mathrm{mL}^{-1}$ for absorption). Naked-eye detection of an analyte is also possible when absorption of the reporter lies in the visible spectral region. The functionalization of branched PEI with dihydrobenzaldehyde provided the polymer with peroxidase-like activity. ${ }^{102}$ In presence 3,3',5,5'-tetramethylbenzidine, as a substrate, and hydrogen peroxide, as a co-factor, the artificial enzyme catalyzed the formation of a product with a strong absorbance at $652 \mathrm{~nm}$. UFH was able to inhibit the catalytic activity of the artificial enzyme, allowing its naked-eye detection in buffer and spectrometric detection in diluted serum.

Molecular imprinting (MIP) is based on the preparation of a polymer in the presence of a target template molecule, which leads to the formation of a cavity that is complementary to the target molecule after its removal from the polymer. When a UFH- 
templated MIP layer was grafted onto the surface of a flat indium tin oxide electrode, the oxidative current of ferrocyanide at the electrode was demonstrated to be sensitive to UFH as well as LMWH in whole blood. ${ }^{103}$ However, large variations in sensitivity existed among the fabricated electrodes, which could be circumvented by using a fluidized bed for graft polymerization onto graphite particles to produce paste electrodes. ${ }^{104}$ These more uniform and reusable electrodes turned out to be efficient for reliable detection in whole blood of both UFH and the LMWH Dalteparin at concentrations ranging from 1 to $8 \mathrm{U} / \mathrm{mL}$. Heparin imprinted thin film were also applied on a quartz crystal microbalance with dissipation (QCM-D) platform, which resonance frequency after excitation is directly linked to the mechanical properties of the sample. ${ }^{105}$ Coagulation time measurements using MIP-based QCM-D provided ultrasensitive, fast, an accurate detection of UFH using only $2 \mu \mathrm{L}$ of human plasma, which compared to the "gold standard" aPTT assay.

\section{Nanoparticle binders}

The unique optoelectronic properties of NPs make them suitable sensors without the use of external binders such as (bio)polymers when the functionalities necessary for its interaction with heparin are covalently bound to the particles' surface. For instance, fluorescent cysteine-capped $\mathrm{CuInS}_{2}$ QDs bound UFH over a large concentration range (i.e., $1.5-12.0 \mu \mathrm{M}$ ) in $2 \%$ FBS, resulting in QDs aggregation and turn-off optical switching at long emission wavelengths (i.e., 610-800 $\mathrm{nm}$ ) that overcome the autofluorescence of biological samples. ${ }^{106}$ Depending on the capping of the particles, UFH could also lead turnon switching of fluorescence. This was the case for glutathione-capped CdTe QDs, which established H-bonds and salt bridges with the oligosaccharide that resulted in increased repulsion forces between the QDs and decreased aggregation. ${ }^{107}$ The previous approaches were combined by using amino-modified silicon NPs that spontaneously self-assembled in presence of gold NPs bearing glutathione, providing therefore dual emissions (i.e., $450 \mathrm{~nm}$ from silicon NPs and $570 \mathrm{~nm}$ ascribed to the aggregation induced fluorescence of gold NPs). ${ }^{108}$ Upon UFH-induced de-aggregation, the fluorescence of cationic silicon NPs remaining unaltered and was used as internal reference, while the fluorescence of gold NPs was quenched and used as a signal probe. Such a ratiometric measurement for UFH allowed its sensitive monitoring, with recoveries of spiked human serum samples in the $99.5 \%-100.7 \%$ range. Another way to achieve high sensitivity was to exploit the ability of large positive charge density of gold NPs to catalyze the luminol oxidation by hydrogen peroxide, which was inhibited upon UFH binding. ${ }^{109}$ Such a strategy of signal amplification led to remarkable LOD of $0.06 \mathrm{ng} / \mathrm{mL}$. Cationic surface groups could also be incorporated during the synthesis of the nanoparticles as for carbon QDs made from o-aminophenol, which exhibited both blue and green fluorescence upon $310 \mathrm{~nm}$ and $420 \mathrm{~nm}$ excitation, respectively. ${ }^{110}$ The blue fluorescence was quenched upon heparin binding, with a calibration plot in buffered water that was linear in the 10 to $100 \mathrm{nM}$ concentration range.

The advantage of organic NPs compared to metallic NPs is the possibility of spatially organizing several components in the nanostructures. Takeuchi et al. described red-green-blue tri-chromophoric fluorescent NPs, from which two distinct FRET events occur through a cationic blue-emitting scaffold and two acceptor molecules, a red-emitting dye embedded in the particles and an anionic green-emitting dye at the surface. ${ }^{11}$ This interior and exterior "dual-FRET" generated full-color emission including white - in an aqueous medium. The displacement of the green-emitting dye upon addition of an increasing amount of UFH led to the gradual suppression of one single FRET channel, shifting the visible response from white to blue via yellowish-white. 


\begin{tabular}{|c|c|c|c|c|c|c|c|}
\hline & RESPONSE & SIGNAL & COMPOSITION & LINEAR RANGE & LOD & TIME & REF \\
\hline \multirow{23}{*}{ 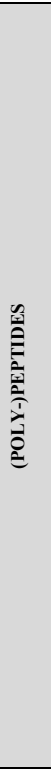 } & Turn-on & Fluorescence & QDs, AT & $0.5-25 \mathrm{nM}$ & $0.1 \mathrm{nM}$ & 1 & 57 \\
\hline & Turn-off & LSPR & Gold NPs, collagen & $5-100 \mu \mathrm{M}$ & 1 & $30 \mathrm{~min}$ & 58 \\
\hline & Ratiometric & Fluorescence & $\begin{array}{l}\text { Pyrene, lysine- and arginine-rich } \\
\text { peptide }\end{array}$ & ' & $34 \mathrm{pM}$ & / & 59 \\
\hline & Ratiometric & Fluorescence & Pyrene, polyarginine & $0-2400 \mathrm{pM}$ & $36 \mathrm{pM}$ & 1 & 60 \\
\hline & Ratiometric & Fluorescence & $\begin{array}{l}\text { Pyrene, lysine- and arginine-rich } \\
\text { peptide }\end{array}$ & $0-24 \mathrm{nM}$ & $2.46 \mathrm{nM}$ & / & 62 \\
\hline & Ratiometric & Fluorescence & Pyrene, polyarginine & I & $1 \mathrm{nM}$ & 1 & ${ }^{63}$ \\
\hline & Turn-on & Fluorescence & $\begin{array}{l}\text { TPE, lysine- and arginine-rich } \\
\text { peptide }\end{array}$ & $0-700 \mathrm{pm}$ & $138.0 \mathrm{pm}$ & l & ${ }_{64}^{64}$ \\
\hline & Turn-on & Fluorescence & $\begin{array}{l}\text { TPE, heparin-specific binding } \\
\text { peptide }\end{array}$ & $0.064-0.32 \mu \mathrm{g} / \mathrm{mL}$ & $3.8 \mathrm{ng} / \mathrm{mL}$ & l & 65 \\
\hline & Ratiometric & Fluorescence, UV & Phloxine B, TPE, protamine & $0-0.8 \mathrm{U} / \mathrm{mL}$ & $0.02 \mathrm{U} / \mathrm{mL}$ & $10 \mathrm{~min}$ & 67 \\
\hline & Turn-off & SERS & $\begin{array}{l}\text { Gold NPs, synthetic cationic } \\
\text { polymer, protamine }\end{array}$ & $0.05-20 \mathrm{ng} / \mathrm{mL}$ & $0.03 \mathrm{ng} / \mathrm{mL}$ & 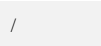 & 68 \\
\hline & Turn-off & SERS & Gold NPs, MBA, polypeptides & $0.2-2.4 \mathrm{U} / \mathrm{mL}$ & $0.042 \mathrm{U} / \mathrm{mL}$ & l & 69 \\
\hline & Turn-off & FRET & $\begin{array}{l}\text { Gold NPs, NaYF4:Yb,Er NPs, } \\
\text { MBA, protamine }\end{array}$ & $0.006-2.0 \mu \mathrm{g} / \mathrm{mL}$ & $0.07 \mathrm{ng} / \mathrm{mL}$ & $50 \mathrm{~min}$ & 70 \\
\hline & Turn-off & Fluorescence & Gold NPs, silicon QDs, protamine & $0.002-1.4 \mu \mathrm{g} / \mathrm{mL}$ & $0.67 \mathrm{ng} / \mathrm{mL}$ & 1 & 71 \\
\hline & Turn-off & Colorimetry & Platinum NPs, protamine & $1-10 \mu \mathrm{M}$ & $0.3 \mu \mathrm{M}$ & $10 \mathrm{~min}$ & 72 \\
\hline & 1 & Potentiometry & Protamine & $0-2.0 \mathrm{U} / \mathrm{mL}$ & $0.06 \mathrm{U} / \mathrm{mL}$ & $200 \mathrm{~s}$ & 73 \\
\hline & Turn-on & Fluorescence & $\begin{array}{l}\mathrm{Tb}^{3+} \text {, ssDNA, heparin-specific } \\
\text { binding peptide }\end{array}$ & $0.01-1 \mu \mathrm{g} / \mathrm{mL}$ & $4.6 \mathrm{ng} / \mathrm{mL}$ & , & 75 \\
\hline & Turn-off & Fluorescence & ssDNA, coralyne & 1 & $75 \mathrm{ng} / \mathrm{mL}, 4 \mathrm{nM}$ & $5 \mathrm{~min}$ & 76 \\
\hline & Turn-off & Fluorescence & ssDNA, coralyne, organic dye & $0.5-160 \mathrm{nM}$ & $0.1 \mathrm{nM}$ & $10 \mathrm{~min}$ & 77 \\
\hline & Turn-off & Fluorescence & ssDNA, coralyne & $0-100 \mathrm{nM}$ & $1 \mathrm{nM}$ & $30 \mathrm{~min}$ & 78 \\
\hline & Turn-on & Fluorescence & Tawain Cobra toxin, aptamer & $18-189 \mathrm{ng} / \mathrm{mL}$ & $8.7 \mathrm{ng} / \mathrm{mL}$ & $5 \mathrm{~min}$ & 80 \\
\hline & Ratiometric & Fluorescence & Carbon QDs, ssDNA & $\begin{array}{l}0.01-2.0 \mu \mathrm{g} / \mathrm{mL}, 0.00125- \\
0.25 \mathrm{U} / \mathrm{mL}\end{array}$ & $9.04 \mathrm{ng} / \mathrm{mL}$ & $10 \mathrm{~min}$ & ${ }^{8 t}$ \\
\hline & Turn-on & Phosphorescence & $\begin{array}{l}\text { Gold NPs, synthetic cationic } \\
\text { polymer, protamine }\end{array}$ & $0.006-25 \mu \mathrm{g} / \mathrm{mL}$ & $6 \mathrm{ng} / \mathrm{mL}$ & $15 \mathrm{~min}$ & 112 \\
\hline & Turn-off & Fluorescence & $\begin{array}{l}\text { Copper nanoclusters, synthetic } \\
\text { cationic polymer, protamine }\end{array}$ & $6-9 \mathrm{ng} / \mathrm{mL}$ & $0.0406 \mathrm{ng} / \mathrm{mL}$ & $1 \mathrm{~min}$ & 113 \\
\hline \multirow{15}{*}{ 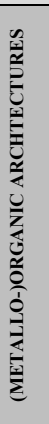 } & Turn-on & Fluorescence & TPE, $\mathrm{Pt}^{3+}$ metallacycle & $0-28 \mu \mathrm{M}$ & / & $/ / 15$ min & $\begin{array}{l}82 \\
83\end{array}$ \\
\hline & Turn-on & Fluorescence & Cationic TPE & $136-180 \mathrm{ng} / \mathrm{mL}$ & $1.53 \mathrm{ng} / \mathrm{mL}$ & $15 \mathrm{~min}$ & ${ }^{83}$ \\
\hline & Ratiometric & Fluorescence & $\begin{array}{l}\text { oligo(p-phenylenevinylene)-based } \\
\text { bis-pyridinium }\end{array}$ & 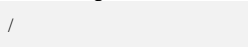 & 年 & l & ${ }_{84}$ \\
\hline & Ratiometric & Fluorescence & Pyrene, cationic micelles & $0-10 \mu \mathrm{M}$ & 1 & 1 & 85 \\
\hline & Turn-on & Fluorescence & AIE-based probe & $0-10 \mu \mathrm{M}$ & $0.08 \mu \mathrm{M}$ & $2 \min$ & 86 \\
\hline & Turn-off & Fluorescence & Cationic coumarin & $14.8-148 \mathrm{nM}$ & 1 & / & ${ }^{87}$ \\
\hline & Turn-off & Fluorescence & Cationic perylene, spermine & $0-5 \mu \mathrm{g} / \mathrm{mL}, 0-1 \mathrm{U} / \mathrm{mL}$ & I & I & 88 \\
\hline & Turn-on & Fluorescence & Pillar[5]arene, methyl orange dye & $8.5-21.2 \mathrm{U} / \mathrm{mL}$ & 1 & / & 89 \\
\hline & Turn-on & Fluorescence, & Graphene oxide, surfen & $100-3000 \mathrm{ng} / \mathrm{mL}$ & $30 \mathrm{ng} / \mathrm{mL}$ & 1 & 90 \\
\hline & Turn-on & $\begin{array}{l}\text { Fluorescence, } \\
\text { colorimetry }\end{array}$ & Thioflavin T & / & $18 \mathrm{nM}$ & । & 91 \\
\hline & 1 & Photoaccoustic & Methylene blue & $0-6.4 \mathrm{U} / \mathrm{mL}$ & $0.28 \mathrm{U} / \mathrm{mL}$ & $32 \mathrm{~s}$ & 92 \\
\hline & Turn-off & SERS & Silver NPs, cationic perylene & $0.1 \mathrm{ng} / \mathrm{mL}-10 \mu \mathrm{g} / \mathrm{mL}$ & $0.08 \mathrm{ng} / \mathrm{mL}$ & 1 & 93 \\
\hline & Turn-on & Fluorescence & AIE-based probe & $\begin{array}{l}0.2-14 \mu \mathrm{g} / \mathrm{mL}, 0.3-2.1 \\
\mathrm{U} / \mathrm{mL}\end{array}$ & $\begin{array}{l}57.6 \mathrm{ng} / \mathrm{mL}, 0.00864 \\
\mathrm{U} / \mathrm{mL}\end{array}$ & $2 \min$ & ${ }^{114}$ \\
\hline & Ratiometric & Fluorescence & Cationic pyrene & $10-100 \mathrm{nM}$ & $8.5 \mathrm{nM}, 153 \mathrm{ng} / \mathrm{mL}$ & $1 \mathrm{~min}$ & 115 \\
\hline & Turn-on & Fluorescence & CdTe QDs, ruthenium complex & $22-77 \mathrm{nM}$ & $0.38 \mathrm{nM}$ & $5 \mathrm{~min}$ & 116 \\
\hline \multirow{18}{*}{ 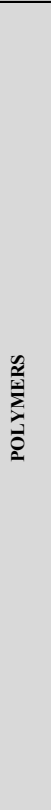 } & Sequential on/off & SERS & Gold-silver NPs, chitosan & $\begin{array}{l}50-800 \mathrm{ng} / \mathrm{mL}, 6.5-104 \\
\mathrm{U} / \mathrm{mL}\end{array}$ & $43.74 \mathrm{ng} / \mathrm{mL}, 5.69 \mathrm{U} / \mathrm{mL}$ & 1 & ${ }_{94}$ \\
\hline & $\begin{array}{l}\text { Ratiometric, lifetime } \\
\text { emission }\end{array}$ & $\begin{array}{l}\text { Fluorescence, } \\
\text { phosphorescence }\end{array}$ & Polyfluorene, iridium complex & Up to $10.9 \mu \mathrm{M}$ & l & l & 95 \\
\hline & Ratiometric & Fluorescence & Polyfluorene, poly-TPE & Up to $10 \mu \mathrm{M}$ & l & l & 96 \\
\hline & Ratiometric & Fluorescence & $\begin{array}{l}\text { Anionic benzoperylene dye, } \\
\text { polyDADMAC }\end{array}$ & $\begin{array}{l}0.4-3.5 \mu \mathrm{M}, 0.048-0.42 \\
\mathrm{U} / \mathrm{mL}\end{array}$ & $50 \mathrm{nM}$ & 1 & 97 \\
\hline & Turn-off & Phosphorescence & Mn-doped ZnS QDs, polybrene & $0.05-1.4 \mathrm{U} / \mathrm{mL}$ & $0.0021 \mathrm{U} / \mathrm{mL}$ & $10 \mathrm{~min}$ & 98 \\
\hline & Turn-on & Fluorescence & DGL, anionic fluorophore & $0-19$ USP & 0.12 USP & 1 & 99 \\
\hline & Tri-channel & $\begin{array}{l}\text { Fluorescence, } \\
\text { absorbance, RRS }\end{array}$ & PEI, phloxine B & $\begin{array}{l}0.001-0.15 \mathrm{U} / \mathrm{mL} \text { (RRS) } \\
0.005-0.3 \mathrm{U} / \mathrm{mL} \\
\text { (fluorescence) } \\
0.01-0.1 \mathrm{U} / \mathrm{mL} \text { (absorbance) }\end{array}$ & $\begin{array}{l}42 \mathrm{nM}(\mathrm{RRS}) \\
0.003 \mathrm{U} / \mathrm{mL} \\
\text { (fluorescence) } \\
0.005 \mathrm{U} / \mathrm{mL} \text { (absorbance) }\end{array}$ & $4 \min$ & 101 \\
\hline & l & Amperometry & MIP & 1 & 1 & l & 103 \\
\hline & I & QCM-D & MIP & / & l & immediate & 105 \\
\hline & l & Voltammetry & MIP & I & l & $60 \mathrm{~s}$ & 104 \\
\hline & Turn-off & Colorimetry & $\begin{array}{l}\text { Branched PEI, fluorogenic } \\
\text { substrate }\end{array}$ & $0.050-1.0 \mu \mathrm{M}$ & $2.5 \mathrm{nM}$ & $10 \mathrm{~min}$ & 102 \\
\hline & Ratiometric & Colorimetric & $\begin{array}{l}\text { Graphene oxide, gold NPs, } \\
\text { polyDADMAC }\end{array}$ & $20-140 \mathrm{ng} / \mathrm{mL}$ & $10.4 \mathrm{ng} / \mathrm{mL}$ & l & ${ }_{117}$ \\
\hline & Turn-on & Fluorescence & $\begin{array}{l}\text { Graphitic carbon nitride QDs, } \\
\text { silver NPs, PEI }\end{array}$ & $0.025-25 \mu \mathrm{M}$ & $8.2 \mathrm{nM}$ & $3 \min$ & H18 \\
\hline & Turn-on & fluorescence & Graphene-QDs, PAMAM & $0.04-1.6 \mu \mathrm{g} / \mathrm{mL}$ & $0.02 \mu \mathrm{g} / \mathrm{mL}$ & $15 \mathrm{~min}$ & 119 \\
\hline & Turn-on & Fluorescence & $\begin{array}{l}\text { Graphene oxide, rhodamine B, } \\
\text { PEI }\end{array}$ & $0.09-0.9 \mathrm{U} / \mathrm{mL}$ & $0.00132 \mathrm{U} / \mathrm{mL}$ & $5 \min$ & 120 \\
\hline & Turn-on & Fluorescence & $\mathrm{Ag}_{2} \mathrm{~S}-\mathrm{QDs}, \mathrm{PEI}$ & $0.669-2.275 \mu \mathrm{M}$ & $0.5 \mathrm{ng} / \mathrm{mL}$ & $1 \mathrm{mn}$ & 121 \\
\hline & Ratiometric & Fluorescence & CdTe-QDs, carbon-QDs, PEI & $\begin{array}{l}50-600 \mathrm{ng} / \mathrm{mL}, 0.1-1.2 \\
\mathrm{U} / \mathrm{mL}\end{array}$ & $0.02 \mu \mathrm{g} / \mathrm{mL}$ & $5 \min$ & 122 \\
\hline & l & Voltammetry & Carbon nanotubes / PEI & $0.1-2 \mathrm{U} / \mathrm{mL}$ & $0.066 \mathrm{U} / \mathrm{mL}$ & immediate & 123 \\
\hline \multirow{7}{*}{ 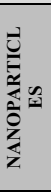 } & Turn-off & Fluorescence & CuInS2 QDs & $\begin{array}{l}0.05-15 \mu \mathrm{M}, 0.17-1.32 \\
\mathrm{U} / \mathrm{mL}\end{array}$ & $12.4 \mathrm{nM}$ & $15 \mathrm{~min}$ & 106 \\
\hline & Turn-on & Fluorescence & Cd-Te QD & $10-100 \mathrm{ng} / \mathrm{mL}$ & $2.0 \mathrm{ng} / \mathrm{mL}$ & $5 \mathrm{~s}$ & 107 \\
\hline & Ratiometric & Fluorescence & Si-NPs, Au-NPs & $6.44-96.6 \mathrm{ng} / \mathrm{mL}$ & $3.29 \mathrm{mg} / \mathrm{mL}$ & $20 \mathrm{~min}$ & 108 \\
\hline & Turn-off & Chemiluminescence & $\mathrm{Au}-\mathrm{NPs}$, luminol & $0.3-16 \mathrm{ng} / \mathrm{mL}$ & $0.06 \mathrm{ng} / \mathrm{mL}$ & $15 \mathrm{~min}$ & 109 \\
\hline & Ratiometric & Fluorescence & C-dots & $10-100 \mathrm{nM}$ & $8.2 \mathrm{nM}$ & 1 & 110 \\
\hline & Ratiometric & Fluorescence & Oligofluorene, PS, DCM & 1 & $8 \mathrm{ng} / \mathrm{mL}$ & 1 & ill \\
\hline & Turn-on & Fluorescence & Au-NPs & $0.18-11.98 \mathrm{U} / \mathrm{mL}$ & $0.08 \mathrm{U} / \mathrm{mL}$ & $5 \mathrm{~min}$ & ${ }^{124}$ \\
\hline
\end{tabular}

Table 1. Recent approaches toward heparin monitoring. Sensors working in whole blood are highlighted in blue. 
From this review, it is clear that significant progress has been made in the neutralization and monitoring of heparin during the past five years, from which emerged new antidotes and sensors that certainly exceed current clinical standards.

The core principle behind the development of heparin antidotes is to mimic positive charges displayed by protamine in order to form inert complexes with the anticoagulant. In the ideal world of heparin neutralization, physicians would like to administer antidotes - even at overdose levels - to patients without fearing immunogenic reactions, toxicity, or limited efficacy. Thus, new heparin antagonists that meet these requirements certainly meet a medical demand. To this end, a broad spectrum of molecular size range been explored, ranging from nanometric particles to small organic molecules. Their current stages of evaluation range from primary assays to clinical phase II trials (Figure 4). Using proteins that are known binders for heparin is an attractive approach that may be tampered by the fact that such therapeutics run the risk of being recognized as foreign by a host immune system. Nevertheless, solutions from protein engineering to overcome immunogenicity exist, like using an immunoglobulin as a carrier molecule to induce unresponsiveness in the immune system. ${ }^{25}$ Ultimately, the main concerns of protein pharmaceuticals come from their cost of production, and the routine handling or unintentional mishandling of therapeutic protein products that potentially compromise their clinical safety and efficacy. ${ }^{126}$ Going down the size scale, the use of linear or dendritic synthetic (bio)-polymers bearing numerous ammonium groups - in order to offer large cationic surfaces for heparin binding through multivalent electrostatic interactions - is the most explored class of protamine surrogates. However, polycations are notorious for poor biocompatibility, and their alkaline nature can lead to the same side-effects encountered with protamine (i.e., toxicity and immunogenicity). Three tactics can help circumvent this issue: i) restricting the number of antidotes' charged residues to minimum necessary to observe reversal activities, ${ }^{29,} 33$ ii) introducing PEG chains on the antidote's scaffolds, which is the best known modification to favorably impact both toxicity and immunogenicity, ${ }^{43,47-49}$ and/or iii) substituting primary ammonium by per-alkylated ammonium, which obviously reduces the overall basicity of the anditodes. $^{35,36,43,47-49}$ At the bottom of the size scale, small cationic molecules certainly are an intriguing class of recently developed reversal agents since their ability to efficiently bind to the anticoagulants has not been demonstrated yet. Their reversal activity may involve other mechanism(s) requiring to be clarified. ${ }^{31,32,34}$ Small molecule drugs have numerous advantages, including well defined structures (in comparison to (bio)-polymers), longer shelf lives (in comparison to proteins), an ease of manufacturing (in comparison to both (bio)-polymers and proteins). At the interface of the two previous class of antidotes lies self-assembled binders, which yield nanoscale multivalent surfaces for heparin binding from the auto-aggregation of small cationic organic molecules. ${ }^{50-56}$ Although this very promising (almost ideal?) approach provides highly efficient, degradable, inexpensive and easy-to-produce binders for heparin, further optimization is still needed to make these selfassembled structures stable enough to operate in highly competitive human blood, which is the ultimate target medium for clinical application. Finally, some of the recently reported reversal agents display a unique feature that FDA-approved protamine does not: the omnipotent ability to neutralize heparin of all sizes. They are either small molecules, polymers or proteins. Whereas inactivated ATs, ${ }^{24}$ highly basic histones, ${ }^{26}$ and foldamers ${ }^{33}$ benefit from a well-defined tertiary structure for an optimized binding event, (dendritic) polymers (i.e., DGLs, ${ }^{45}$ UHRAs, ${ }^{47-49}$ and PEGylated PMAPTAC ${ }^{43}$ ) take advantage of their flexibility in order to form strong inert complexes with UFH, LMWHs, and fondaparinux. As mentioned above, the mechanism(s) behind the universal heparin reversal activity of small molecules such as surfen ${ }^{34}$ or PER977 ${ }^{31,32}$ has yet to be elucidated.

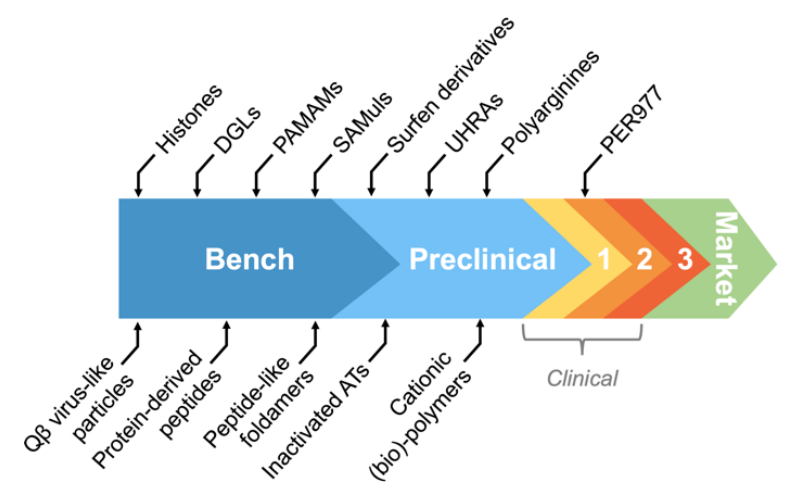

Figure 4. Progress in the development of recent protamine surrogates. Bench $=$ in vitro experiments, preclinical $=$ animal studies, clinical $=$ human trials.

Heparin neutralization and sensing are two sides of the same coin: the primary event is the binding of the anticoagulant, which then translates into optical, electrical, or acoustic outputs (Figure 3). Obviously, the biocompatibility of the receptor is no longer an issue for in vitro applications, and a larger variety of scaffolds in comparison with in vivo applications can therefore be considered, including for instance metallic nanoparticles. The developed sensors should deliver the overall amount of heparin in the tested fluids to surpass traditional laboratory assays, which are indirect and therefore not sufficiently accurate and reliable because of potential interference from other factors (vide supra). In this context, numerous binding scaffolds and sensing mechanisms have recently been explored with success (Table 1), with for instance appreciable linear detection ranges that can

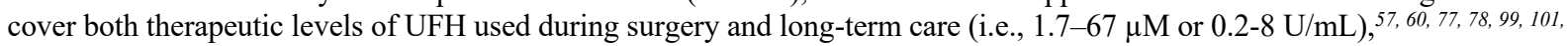
$114,118,124$ the total recovery of spiked heparin in serum or plasma samples, $57,83,86,108$ or extraordinary low limits of detection in some cases (i.e., in the picomolar range). ${ }^{59,}{ }^{60}$ In addition, more than $50 \%$ of all reported measurement times are very short (i.e., less than or equal to five minutes), which may be of vital importance in the stressful context of major vascular surgery 
and/or bleeding complications. Remarkably, it has been shown since 2015 that it is possible to quantify overall amount of UFH in whole blood - which is the "holy grail" for chemists - by exploiting either potentiometric ${ }^{73}$, amperometric, ${ }^{103}$ voltammetric, ${ }^{104}$ photoacoustic,${ }^{92}$ or fluorescent signals. ${ }^{99}$ Although monitoring of LMWHs is not routine, it is highly recommended when accurate dosing is especially important, such as in the context of renal impairment, or in case of bleeding and thrombotic outcomes. ${ }^{127}$ It is appreciable that a few reported sensors also work with these shorter GAGs since LMWHs has little effect on the aPTT coagulation test, ${ }^{88,92,103,104}$ which is most frequently used because of its relative accessibility, ease of automation, and cost. ${ }^{128}$ The accuracy of sensors is affected by a variety of factors such as instrument, sensor concentration, or working media. Each factor of variability can actually be addressed. Ratiometric sensors provide internal calibration through dual-channel outputs that are independent of the instrument used, $59,60,67,95,110,111$ intramolecular signaling events give responses that are independent of the concentration of the chemosensor, ${ }^{63}$ and long emission wavelengths (i.e., red-light) overcome the autofluorescence of biological samples. ${ }^{86-88,106}$ In addition, multidimensional platforms, which offer more than one transduction channel and thus combine the advantages of distinct output signals, increase the accuracy of the sensors. ${ }^{101}$ Beyond the ability to routinely monitor heparin, the assessment of its purity is mandatory in order to prevent public health disasters. Indeed, the use of UFH contaminated with OSCS, ChS, dermatan sulfate, and HA in patients undergoing dialysis resulted in serious acute hypersensitivity reactions (including 81 deaths in U.S. patients) during the late $2000 \mathrm{~s} .{ }^{61}$ FDA currently recommends highly sophisticated and expensive orthogonal methods such as high performance liquid chromatography combined with nuclear magnetic and mass spectroscopy to detect identify contaminants in UFH. ${ }^{129}$ In order to provide less costly and easier to implement quality controls, some of the sensors have been upgraded toward i) the detection of very low concentrations of OSCS contaminant by exploiting the selective degradation of UFH by the heparinase enzyme, ${ }^{62,65,75}$ or ii) the differentiation of mixtures of GAGs by using an array of sensors. ${ }^{100}$ Finally, the implementability of the reported sensors at the point-of-care has yet to be demonstrated. The sensing devices should be as miniaturized as possible. Nowadays, portable devices for all types of output signal listed in table 1 exist, including for photoaccoustic imaging. ${ }^{130}$ In addition, the sensing devices should not involve tedious handling and/or instable substrates. In this regard, future clinical development should focus on devices that include robust chemical components such as, for instance, small organic molecules or abiotic (imprinted) polymers (Table 1). To conclude, the ambition of this review is a better exposure of a very active and creative field that now demands close partnerships between physicians, biologists and chemists if some of these reported advances are to be translated in clinical settings.

\section{Acknowledgements}

This work was supported by the Centre National de la Recherche Scientifique (CNRS), and the Université de Lyon. The authors gratefully acknowledge J. Leclaire (Université de Lyon) for helpful comments and corrections on the manuscript.

\section{Keywords}

Anticoagulants: commonly known as blood thinners, they are chemical substances that retard or inhibit the coagulation of the blood.

Coagulation cascade: cascade of enzymic events that leads to polymerization of fibrin and the activation of platelets, and ultimately a blood clot.

Glycosaminoglycans (GAGs): linear polysaccharides consisting of repeating units consisting of an amino sugar along with a uronic sugar or galactose.

Heparin: biopolymer with anticoagulant activity, which belongs to the family of GAGs.

Protamine: small arginine-rich protein extracted from milt that neutralizes heparin's anticoagulant activity.

Heparin antidote: a medicine given to counteract the anticoagulant activity of heparin.

Heparin sensor: device that transforms the concentration of heparin into an analytically useful signal.

Detection Limit (LOD): lowest quantity of heparin that can be distinguished from the absence of heparin with a stated confidence level.

Unit of heparin (U): dose of the drug required to produce a specific level of anticoagulation.

\section{References}

1. De Caterina, R., Husted, S., Wallentin, L., Agnelli, G., Bachmann, F., Baigent, C., Jespersen, J., Kristensen, S. D., Montalescot, G., Siegbahn, A., Verheugt, F. W., and Weitz, J. (2007) Anticoagulants in heart disease: current status and perspectives, Eur. Heart J. 28, 880-913.

2. Bussey, H., and Francis, J. L. (2004) Heparin overview and issues, Pharmacotherapy 24, 103s-107s.

3. Weitz, J. I. (1997) Low-Molecular-Weight Heparins, N. Engl. J. Med. 337, 688-699.

4. Francis, C. W. (2007) Prophylaxis for Thromboembolism in Hospitalized Medical Patients, N. Engl. J. Med. 356, 14381444. 
5. Vincentelli, A., Jude, B., and Belisle, S. (2006) Antithrombotic therapy in cardiac surgery, Can. J. Anaesth. 53, S89-102.

6. Suranyi, M., and Chow, J. S. (2010) Review: anticoagulation for haemodialysis, Nephrology (Carlton) 15, 386-392.

7. (2006) Comparison of Fondaparinux and Enoxaparin in Acute Coronary Syndromes, N. Engl. J. Med. 354, 1464-1476.

8. Schiele, F., Meneveau, N., Seronde, M. F., Descotes-Genon, V., Dutheil, J., Chopard, R., Ecarnot, F., and Bassand, J. P. (2010) Routine use of fondaparinux in acute coronary syndromes: a 2-year multicenter experience, Am. Heart J. 159, 190-198.

9. Melnikova, I. (2009) The anticoagulants market, Nature Reviews Drug Discovery 8, 353.

10. Sokolowska, E., Kalaska, B., Miklosz, J., and Mogielnicki, A. (2016) The toxicology of heparin reversal with protamine: past, present and future, Expert Opin. Drug Metab. Toxicol. 12, 897-909.

11. Patriquin, C., and Crowther, M. (2013) 26 - Antithrombotic Agents, In Consultative Hemostasis and Thrombosis (Third Edition) (Kitchens, C. S., Kessler, C. M., and Konkle, B. A., Eds.), pp 477-495, W.B. Saunders, Philadelphia.

12. Makris, M., Van Veen, J. J., Tait, C. R., Mumford, A. D., and Laffan, M. (2013) Guideline on the management of bleeding in patients on antithrombotic agents, Br. J. Haematol. 160, 35-46.

13. Giangrande, P. L. (2002) Fondaparinux (Arixtra): a new anticoagulant, Int. J. Clin. Pract. 56, 615-617.

14. Porsche, R., and Brenner, Z. R. (1999) Allergy to protamine sulfate, Heart Lung 28, 418-428.

15. Health, E. M. A. S. M. (2012) European Medicines Agency completes review of protamine-containing medicines.

16. (2017) WHO model list of essential medicines, 20th list, World Health Organization.

17. Despotis, G. J., Gravlee, G., Filos, K., and Levy, J. (1999) Anticoagulation monitoring during cardiac surgery: a review of current and emerging techniques, Anesthesiology 91, 1122-1151.

18. Raymond, P. D., Ray, M. J., Callen, S. N., and Marsh, N. A. (2003) Heparin monitoring during cardiac surgery. Part 2: Calculating the overestimation of heparin by the activated clotting time, Perfusion 18, 277-281.

19. Vandiver, J. W., and Vondracek, T. G. (2012) Antifactor Xa levels versus activated partial thromboplastin time for monitoring unfractionated heparin, Pharmacotherapy 32, 546-558.

20. Murray, D. J., Brosnahan, W. J., Pennell, B., Kapalanski, D., Weiler, J. M., and Olson, J. (1997) Heparin detection by the activated coagulation time: a comparison of the sensitivity of coagulation tests and heparin assays, J. Cardiothorac. Vasc. Anesth. 11, 24-28.

21. Vera-Aguilera, J., Yousef, H., Beltran-Melgarejo, D., Teng, T. H., Jan, R., Mok, M., Vera-Aguilera, C., and MorenoAguilera, E. (2016) Clinical Scenarios for Discordant Anti-Xa, Adv. Hematol. 2016, 6.

22. Bromfield, S. M., Wilde, E., and Smith, D. K. (2013) Heparin sensing and binding - taking supramolecular chemistry towards clinical applications, Chem. Soc. Rev. 42, 9184-9195.

23. Esko, J. D., Kimata, K., and Lindahl, U. (2009) Proteoglycans and Sulfated Glycosaminoglycans, In Essentials of Glycobiology, Cold Spring Harbor (NY).

24. Bourti, Y., Fazavana, J., Armand, M., Saller, F., Lasne, D., Borgel, D., and Bianchini, E. P. (2016) Inactivated antithrombins as fondaparinux antidotes: a promising alternative to haemostatic agents as assessed in vitro in a thrombin-generation assay, Thromb. Haemost. 116, 452-460.

25. Bianchini, E. P., Sebestyen, A., Abache, T., Bourti, Y., Fontayne, A., Richard, V., Tamion, F., Plantier, J.-L., Doguet, F., and Borgel, D. (2018) Inactivated antithombin as anticoagulant reversal in a rat model of cardiopulmonary bypass: a potent and potentially safer alternative to protamine, Br. J. Haematol. 180, 715-720.

26. Longstaff, C., Hogwood, J., Gray, E., Komorowicz, E., Varjú, I., Varga, Z., and Kolev, K. (2016) Neutralisation of the anticoagulant effects of heparin by histones in blood plasma and purified systems, Thromb. Haemost. 115, 591-599.

27. Cheong, H. Y., Groner, M., Hong, K., Lynch, B., Hollingsworth, W. R., Polonskaya, Z., Rhee, J.-K., Baksh, M. M., Finn, M. G., Gale, A. J., and Udit, A. K. (2017) Heparin Binding to an Engineered Virus-like Nanoparticle Antagonist, Biomacromolecules 18, 4113-4120.

28. Corredor, M., Bonet, R., Moure, A., Domingo, C., Bujons, J., Alfonso, I., Pérez, Y., and Messeguer, À. (2016) Cationic Peptides and Peptidomimetics Bind Glycosaminoglycans as Potential Sema3A Pathway Inhibitors, Biophys. J. 110, 1291-1303.

29. Li, T., Meng, Z., Zhu, X., Gan, H., Gu, R., Wu, Z., Li, J., Zheng, Y., Liu, T., Han, P., Han, S., and Dou, G. (2015) New synthetic peptide with efficacy for heparin reversal and low toxicity and immunogenicity in comparison to protamine sulfate, Biochem. Biophys. Res. Commun. 467, 497-502.

30. Kalathottukaren, M. T., Creagh, A. L., Abbina, S., Lu, G., Karbarz, M. J., Pandey, A., Conley, P. B., Kizhakkedathu, J. N., and Haynes, C. (2018) Comparison of reversal activity and mechanism of action of UHRA, andexanet, and PER977 on heparin and oral FXa inhibitors, Blood advances 2, 2104-2114.

31. Ansell, J. E., Laulicht, B. E., Bakhru, S. H., Hoffman, M., Steiner, S. S., and Costin, J. C. (2016) Ciraparantag safely and completely reverses the anticoagulant effects of low molecular weight heparin, Thromb. Res. 146, 113-118.

32. Sullivan, D. W., Jr., Gad, S. C., Laulicht, B., Bakhru, S., and Steiner, S. (2015) Nonclinical Safety Assessment of PER977: A Small Molecule Reversal Agent for New Oral Anticoagulants and Heparins, Int. J. Toxicol. 34, 308-317.

33. Montalvo, G. L., Zhang, Y., Young, T. M., Costanzo, M. J., Freeman, K. B., Wang, J., Clements, D. J., Magavern, E., Kavash, R. W., Scott, R. W., Liu, D., and DeGrado, W. F. (2014) De Novo Design of Self-Assembling Foldamers That Inhibit Heparin-Protein Interactions, ACS Chem. Biol. 9, 967-975.

34. Weiss, R. J., Gordts, P. L. S. M., Le, D., Xu, D., Esko, J. D., and Tor, Y. (2015) Small molecule antagonists of cell-surface heparan sulfate and heparin-protein interactions, Chem. Sci. 6, 5984-5993.

35. Kalaska, B., Kaminski, K., Sokolowska, E., Czaplicki, D., Kujdowicz, M., Stalinska, K., Bereta, J., Szczubialka, K., Pawlak, D., Nowakowska, M., and Mogielnicki, A. (2015) Nonclinical Evaluation of Novel Cationically Modified Polysaccharide Antidotes for Unfractionated Heparin, PLoS One 10, e0119486.

36. Sokolowska, E., Kalaska, B., Kaminski, K., Lewandowska, A., Blazejczyk, A., Wietrzyk, J., Kasacka, I., Szczubialka, K., Pawlak, D., Nowakowska, M., and Mogielnicki, A. (2016) The Toxicokinetic Profile of Dex40-GTMAC3-a Novel Polysaccharide Candidate for Reversal of Unfractionated Heparin, Front. Pharmacol. 7. 
37. Lorkowska-Zawicka, B., Kamiński, K., Ciejka, J., Szczubiałka, K., Białas, M., Okoń, K., Adamek, D., Nowakowska, M., Jawień, J., Olszanecki, R., and Korbut, R. (2014) Inactivation of heparin by cationically modified chitosan, Mar. Drugs 12, 3953-3969.

38. Kamiński, K., Kałaska, B., Koczurkiewicz, P., Michalik, M., Szczubiałka, K., Mogielnicki, A., Buczko, W., and Nowakowska, M. (2014) New arginine substituted derivative of poly(allylamine hydrochloride) for heparin reversal, MedChemComm 5, 489-495.

39. Robison, A. D., Sun, S., Poyton, M. F., Johnson, G. A., Pellois, J. P., Jungwirth, P., Vazdar, M., and Cremer, P. S. (2016) Polyarginine Interacts More Strongly and Cooperatively than Polylysine with Phospholipid Bilayers, J. Phys. Chem. B 120, 9287-9296.

40. Mitchell, D. J., Kim, D. T., Steinman, L., Fathman, C. G., and Rothbard, J. B. (2000) Polyarginine enters cells more efficiently than other polycationic homopolymers, J. Pept. Res. 56, 318-325.

41. Pasut, G., and Veronese, F. M. (2012) State of the art in PEGylation: the great versatility achieved after forty years of research, J. Control. Release 161, 461-472.

42. Välimäki, S., Khakalo, A., Ora, A., Johansson, L.-S., Rojas, O. J., and Kostiainen, M. A. (2016) Effect of PEG-PDMAEMA Block Copolymer Architecture on Polyelectrolyte Complex Formation with Heparin, Biomacromolecules 17, 28912900.

43. Kalaska, B., Kaminski, K., Miklosz, J., Yusa, S.-i., Sokolowska, E., Blazejczyk, A., Wietrzyk, J., Kasacka, I., Szczubialka, K., Pawlak, D., Nowakowska, M., and Mogielnicki, A. (2016) Heparin-binding copolymer reverses effects of unfractionated heparin, enoxaparin, and fondaparinux in rats and mice, Trans. Res. 177, 98-112.e110.

44. Bromfield, S. M., Posocco, P., Fermeglia, M., Tolosa, J., Herreros-López, A., Pricl, S., Rodríguez-López, J., and Smith, D. K. (2014) Shape-Persistent and Adaptive Multivalency: Rigid Transgeden (TGD) and Flexible PAMAM Dendrimers for Heparin Binding, Chem. Eur. J. 20, 9666-9674.

45. Ourri, B., Francoia, J. P., Monard, G., Gris, J. C., Leclaire, J., and Vial, L. (2019) Dendrigraft of Poly-l-lysine as a Promising Candidate To Reverse Heparin-based Anticoagulants in Clinical Settings, ACS Med. Chem. Lett. 10, 917-922.

46. Jones, C. F., Campbell, R. A., Franks, Z., Gibson, C. C., Thiagarajan, G., Vieira-de-Abreu, A., Sukavaneshvar, S., Mohammad, S. F., Li, D. Y., Ghandehari, H., Weyrich, A. S., Brooks, B. D., and Grainger, D. W. (2012) Cationic PAMAM dendrimers disrupt key platelet functions, Mol. Pharm. 9, 1599-1611.

47. Shenoi, R. A., Kalathottukaren, M. T., Travers, R. J., Lai, B. F. L., Creagh, A. L., Lange, D., Yu, K., Weinhart, M., Chew, B. H., Du, C., Brooks, D. E., Carter, C. J., Morrissey, J. H., Haynes, C. A., and Kizhakkedathu, J. N. (2014) Affinitybased design of a synthetic universal reversal agent for heparin anticoagulants, Sci. Transl. Med. 6, 260ra150.

48. Kalathottukaren, M. T., Abraham, L., Kapopara, P. R., Lai, B. F. L., Shenoi, R. A., Rosell, F. I., Conway, E. M., Pryzdial, E. L. G., Morrissey, J. H., Haynes, C. A., and Kizhakkedathu, J. N. (2017) Alteration of blood clotting and lung damage by protamine are avoided using the heparin and polyphosphate inhibitor UHRA, Blood 129, 1368-1379.

49. Kalathottukaren, M. T., Abbina, S., Yu, K., Shenoi, R. A., Creagh, A. L., Haynes, C., and Kizhakkedathu, J. N. (2017) A Polymer Therapeutic Having Universal Heparin Reversal Activity: Molecular Design and Functional Mechanism, Biomacromolecules 18, 3343-3358.

50. Smith, D. K. (2018) From fundamental supramolecular chemistry to self-assembled nanomaterials and medicines and back again - how Sam inspired SAMul, Chem. Commun. 54, 4743-4760.

51. Vieira, V. M. P., Liljeström, V., Posocco, P., Laurini, E., Pricl, S., Kostiainen, M. A., and Smith, D. K. (2017) Emergence of highly-ordered hierarchical nanoscale aggregates on electrostatic binding of self-assembled multivalent (SAMul) cationic micelles with polyanionic heparin, J. Mater. Chem. B 5, 341-347.

52. Bromfield, S. M., Posocco, P., Chan, C. W., Calderon, M., Guimond, S. E., Turnbull, J. E., Pricl, S., and Smith, D. K. (2014) Nanoscale self-assembled multivalent (SAMul) heparin binders in highly competitive, biologically relevant, aqueous media, Chem. Sci. 5, 1484-1492.

53. Albanyan, B., Laurini, E., Posocco, P., Pricl, S., and Smith, D. K. (2017) Self-Assembled Multivalent (SAMul) Polyanion Binding - Impact of Hydrophobic Modifications in the Micellar Core on DNA and Heparin Binding at the Peripheral Cationic Ligands, Chem. Eur. J. 23, 6391-6397.

54. Rodrigo, A. C., Bromfield, S. M., Laurini, E., Posocco, P., Pricl, S., and Smith, D. K. (2017) Morphological control of selfassembled multivalent (SAMul) heparin binding in highly competitive media, Chem. Commun. 53, 6335-6338.

55. Fechner, L. E., Albanyan, B., Vieira, V. M. P., Laurini, E., Posocco, P., Pricl, S., and Smith, D. K. (2016) Electrostatic binding of polyanions using self-assembled multivalent (SAMul) ligand displays - structure-activity effects on DNA/heparin binding, Chem. Sci. 7, 4653-4659.

56. Thornalley, K. A., Laurini, E., Pricl, S., and Smith, D. K. (2018) Enantiomeric and Diastereomeric Self-Assembled Multivalent Nanostructures: Understanding the Effects of Chirality on Binding to Polyanionic Heparin and DNA, Angew. Chem. Int. Ed. 57, 8530-8534.

57. Dong, S., Liu, X., Zhang, Q., Zhao, W., Zong, C., Liang, A., and Gai, H. (2017) Sensing Active Heparin by Counting Aggregated Quantum Dots at Single-Particle Level, ACS Sensors 2, 80-86.

58. Unser, S., Holcomb, S., Cary, R., and Sagle, L. (2017) Collagen-Gold Nanoparticle Conjugates for Versatile Biosensing, Sensors 17, 378.

59. Kim, D.-H., Park, Y. J., Jung, K. H., and Lee, K.-H. (2014) Ratiometric Detection of Nanomolar Concentrations of Heparin in Serum and Plasma Samples Using a Fluorescent Chemosensor Based on Peptides, Anal. Chem. 86, 6580-6586.

60. Thirupathi, P., Neupane, L. N., and Lee, K.-H. (2015) Fluorescent peptide-based sensors for the ratiometric detection of nanomolar concentration of heparin in aqueous solutions and in serum, Anal. Chim. Acta 873, 88-98.

61. Blossom, D. B., Kallen, A. J., Patel, P. R., Elward, A., Robinson, L., Gao, G., Langer, R., Perkins, K. M., Jaeger, J. L., Kurkjian, K. M., Jones, M., Schillie, S. F., Shehab, N., Ketterer, D., Venkataraman, G., Kishimoto, T. K., Shriver, Z., McMahon, A. W., Austen, K. F., Kozlowski, S., Srinivasan, A., Turabelidze, G., Gould, C. V., Arduino, M. J., 
and Sasisekharan, R. (2008) Outbreak of Adverse Reactions Associated with Contaminated Heparin, N. Engl. J. Med. $359,2674-2684$

62. Mehta, P. K., Lee, H., and Lee, K.-H. (2017) Highly sensitive ratiometric detection of heparin and its oversulfated chondroitin sulfate contaminant by fluorescent peptidyl probe, Biosens. Bioelectron. 91, 545-552.

63. Thirupathi, P., Park, J.-Y., Neupane, L. N., Kishore, M. Y. L. N., and Lee, K.-H. (2015) Pyrene Excimer-Based Peptidyl Chemosensors for the Sensitive Detection of Low Levels of Heparin in 100\% Aqueous Solutions and Serum Samples, ACS Appl. Mater. Interfaces 7, 14243-14253.

64. Lee, H., In, B., Mehta, P. K., Kishore, M. Y. L. N., and Lee, K.-H. (2018) Dual Role of a Fluorescent Peptidyl Probe Based on Self-Assembly for the Detection of Heparin and for the Inhibition of the Heparin-Digestive Enzyme Reaction, ACS Appl. Mater. Interfaces 10, 2282-2290.

65. Ding, Y., Shi, L., and Wei, H. (2015) A "turn on" fluorescent probe for heparin and its oversulfated chondroitin sulfate contaminant, Chem. Sci. 6, 6361-6366.

66. Lamari, F. N., Theocharis, A. D., Asimakopoulou, A. P., Malavaki, C. J., and Karamanos, N. K. (2006) Metabolism and biochemical/physiological roles of chondroitin sulfates: analysis of endogenous and supplemental chondroitin sulfates in blood circulation, Biomed. Chromatogr. 20, 539-550.

67. Zhao, L., Wang, T., Wu, Q., Liu, Y., Chen, Z., and Li, X. (2017) Fluorescent Strips of Electrospun Fibers for Ratiometric Sensing of Serum Heparin and Urine Trypsin, ACS Appl. Mater. Interfaces 9, 3400-3410.

68. Zhang, C., Liang, X., You, T., Yang, N., Gao, Y., and Yin, P. (2017) An ultrasensitive "turn-off" SERS sensor for quantitatively detecting heparin based on 4-mercaptobenzoic acid functionalized gold nanoparticles, Anal. Methods 9, 2517-2522.

69. Qu, G., Zhang, G., Wu, Z., Shen, A., Wang, J., and Hu, J. (2014) A "turn-off” SERS assay of heparin with high selectivity based on heparin-peptide complex and Raman labelled gold nanoparticles, Biosens. Bioelectron. 60, 124-129.

70. Long, Q., Zhao, J., Yin, B., Li, H., Zhang, Y., and Yao, S. (2015) A novel label-free upconversion fluorescence resonance energy transfer-nanosensor for ultrasensitive detection of protamine and heparin, Anal. Biochem. 477, 28-34.

71. Peng, X., Long, Q., Li, H., Zhang, Y., and Yao, S. (2015) “Turn on-off” fluorescent sensor for protamine and heparin based on label-free silicon quantum dots coupled with gold nanoparticles, Sensors Actuators B: Chem. 213, 131-138.

72. You, J.-G., Liu, Y.-W., Lu, C.-Y., Tseng, W.-L., and Yu, C.-J. (2017) Colorimetric assay of heparin in plasma based on the inhibition of oxidase-like activity of citrate-capped platinum nanoparticles, Biosens. Bioelectron. 92, 442-448.

73. Lei, J., Ding, J., Chen, Y., and Qin, W. (2015) Potentiometric flow injection sensing system for determination of heparin based on current-controlled release of protamine, Anal. Chim. Acta 858, 60-65.

74. Abramova, N., and Bratov, A. (2015) Title Monitoring Protamine-Heparin Interactions Using Microcapillary Impedimetric Sensor, Electroanalysis 27, 663-669.

75. Hu, Y., Guo, W., Ding, Y., Cheng, H., and Wei, H. (2016) Modulating luminescence of Tb3 + with biomolecules for sensing heparin and its contaminant OSCS, Biosens. Bioelectron. 86, 858-863.

76. Hung, S.-Y., and Tseng, W.-L. (2014) A polyadenosine-coralyne complex as a novel fluorescent probe for the sensitive and selective detection of heparin in plasma, Biosens. Bioelectron. 57, 186-191.

77. Jiang, H., Wang, G., and Zhang, X. (2015) Detection of heparin based on the conformational switch of DNA, Anal. Methods 7, $7852-7857$.

78. Chen, M., Ma, C., Zhao, H., and Wang, K. (2019) Label-free and sensitive detection of coralyne and heparin based on target-induced G-quadruplex formation, Anal. Methods 11, 1331-1337.

79. Kuo, C.-Y., and Tseng, W.-L. (2013) Adenosine-based molecular beacons as light-up probes for sensing heparin in plasma, Chem. Commun. 49, 4607-4609.

80. Shi, Y.-J., Wang, L.-J., Lee, Y.-C., Huang, C.-H., Hu, W.-P., and Chang, L.-S. (2018) A Turn-on Fluorescence Sensor for Heparin Detection Based on a Release of Taiwan Cobra Cardiotoxin from a DNA Aptamer or Adenosine-Based Molecular Beacon, Molecules (Basel, Switzerland) 23, 460.

81. Huang, J., Li, F., Guo, R., Chen, Y., Wang, Z., Zhao, C., Zheng, Y., Weng, S., and Lin, X. (2018) A signal-on ratiometric fluorometric heparin assay based on the direct interaction between amino-modified carbon dots and DNA, Microchim. Acta 185, 260.

82. Chen, L.-J., Ren, Y.-Y., Wu, N.-W., Sun, B., Ma, J.-Q., Zhang, L., Tan, H., Liu, M., Li, X., and Yang, H.-B. (2015) Hierarchical Self-Assembly of Discrete Organoplatinum(II) Metallacycles with Polysaccharide via Electrostatic Interactions and Their Application for Heparin Detection, J. Am. Chem. Soc. 137, 11725-11735.

83. Zheng, J., Ye, T., Chen, J., Xu, L., Ji, X., Yang, C., and He, Z. (2017) Highly sensitive fluorescence detection of heparin based on aggregation-induced emission of a tetraphenylethene derivative, Biosens. Bioelectron. 90, 245-250.

84. Dey, N., Samanta, S. K., and Bhattacharya, S. (2017) Heparin triggered dose dependent multi-color emission switching in water: a convenient protocol for heparinase I estimation in real-life biological fluids, Chem. Commun. 53, 1486-1489.

85. Chan, C. W., and Smith, D. K. (2016) Pyrene-based heparin sensors in competitive aqueous media - the role of selfassembled multivalency (SAMul), Chem. Commun. 52, 3785-3788.

86. Yang, S., Gao, T., Dong, J., Xu, H., Gao, F., Chen, Q., Gu, Y., and Zeng, W. (2017) A novel water-soluble AIE-based fluorescence probe with red emission for the sensitive detection of heparin in aqueous solution and human serum samples, Tetrahedron Lett. 58, 3681-3686.

87. Jana, P., Radhakrishna, M., Khatua, S., and Kanvah, S. (2018) A "turn-off" red-emitting fluorophore for nanomolar detection of heparin, Phys. Chem. Chem. Phys. 20, 13263-13270.

88. Warttinger, U., Giese, C., Harenberg, J., Holmer, E., and Krämer, R. (2016) A fluorescent probe assay (Heparin Red) for direct detection of heparins in human plasma, Anal. Bioanal. Chem. 408, 8241-8251.

89. Välimäki, S., Beyeh, N. K., Linko, V., Ras, R. H. A., and Kostiainen, M. A. (2018) A supramolecular host-guest complex for heparin binding and sensing, Nanoscale 10, 14022-14030. 
90. Wang, Y.-T., and Tseng, W.-L. (2017) Surfen-Assembled Graphene Oxide for Fluorescence Turn-On Detection of Sulfated Glycosaminoglycans in Biological Matrix, ACS Sensors 2, 748-756.

91. Mudliar, N. H., and Singh, P. K. (2016) Emissive H-Aggregates of an Ultrafast Molecular Rotor: A Promising Platform for Sensing Heparin, ACS Appl. Mater. Interfaces 8, 31505-31509.

92. Wang, J., Chen, F., Arconada-Alvarez, S. J., Hartanto, J., Yap, L.-P., Park, R., Wang, F., Vorobyova, I., Dagliyan, G., Conti, P. S., and Jokerst, J. V. (2016) A Nanoscale Tool for Photoacoustic-Based Measurements of Clotting Time and Therapeutic Drug Monitoring of Heparin, Nano Lett. 16, 6265-6271.

93. Ji, W., Zhang, X., Zhao, J., Gao, Y., Song, W., and Ozaki, Y. (2018) In situ formation of SERS hot spots by a bis-quaternized perylene dye: a simple strategy for highly sensitive detection of heparin over a wide concentration range, Analyst $143,1899-1905$.

94. Zeng, Y., Pei, J.-J., Wang, L.-H., Shen, A.-G., and Hu, J.-M. (2015) A sensitive sequential 'on/off' SERS assay for heparin with wider detection window and higher reliability based on the reversed surface charge changes of functionalized Au@Ag nanoparticles, Biosens. Bioelectron.66, 55-61.

95. Jiang, J., Zhang, C., Lin, W., Liu, Y., Liu, S., Xu, Y., Zhao, Q., and Huang, W. (2015) Long-Lived Phosphorescent Iridium(III) Complexes Conjugated with Cationic Polyfluorenes for Heparin Sensing and Cellular Imaging, Macromol. Rapid Commun. 36, 640-646.

96. Shi, J., Wu, Y., Tong, B., Zhi, J., and Dong, Y. (2014) Tunable fluorescence upon aggregation: Photophysical properties of cationic conjugated polyelectrolytes containing AIE and ACQ units and their use in the dual-channel quantification of heparin, Sensors Actuators B: Chem. 197, 334-341.

97. Yang, M., Chen, J., Zhou, H., Li, W., Wang, Y., Li, J., Zhang, C., Zhou, C., and Yu, C. (2016) Polycation-induced benzoperylene probe excimer formation and the ratiometric detection of heparin and heparinase, Biosens. Bioelectron. 75, 404-410.

98. Zhang, Z., Miao, Y., Zhang, Q., Lian, L., and Yan, G. (2015) Selective room temperature phosphorescence detection of heparin based on manganese-doped zinc sulfide quantum dots/polybrene self-assembled nanosensor, Biosens. Bioelectron. 68, 556-562.

99. Francoia, J.-P., Pascal, R., and Vial, L. (2015) Monitoring clinical levels of heparin in human blood samples with an indicator-displacement assay, Chem. Commun. 51, 1953-1956.

100. Francoia, J.-P., and Vial, L. (2015) A KISS (keep it simple, sensor) array for glycosaminoglycans, Chem. Commun. 51, 17544-17547.

101. Ling, Y., Gao, Z. F., Zhou, Q., Li, N. B., and Luo, H. Q. (2015) Multidimensional Optical Sensing Platform for Detection of Heparin and Reversible Molecular Logic Gate Operation Based on the Phloxine B/Polyethyleneimine System, Anal. Chem. 87, 1575-1581.

102. Yin, M., Duan, Z., Zhang, C., Feng, L., Wan, Y., Cai, Y., Liu, H., Li, S., and Wang, H. (2019) A visualized colorimetric detection strategy for heparin in serum using a metal-free polymer nanozyme, Microchem. J. 145, 864-871.

103. Yoshimi, Y., Inaba, R., Ogawa, T., Yoshino, W., Inoue, M., and Kuwana, K. (2016) Stabilized sensing of heparin in whole blood using the 'gate effect' of heparin-imprinted polymer grafted onto an electrode, Mol. Impr. 4, 13.

104. Yoshimi, Y., Yagisawa, Y., Yamaguchi, R., and Seki, M. (2018) Blood heparin sensor made from a paste electrode of graphite particles grafted with molecularly imprinted polymer, Sensors Actuators B: Chem. 259, 455-462.

105. Hussain, M. (2015) Ultra-sensitive detection of heparin via aPTT using plastic antibodies on QCM-D platform, $R S C a d v$. $5,54963-54970$.

106. Liu, Z., Ma, Q., Wang, X., Lin, Z., Zhang, H., Liu, L., and Su, X. (2014) A novel fluorescent nanosensor for detection of heparin and heparinase based on CuInS2 quantum dots, Biosens. Bioelectron. 54, 617-622.

107. Rezaei, B., Shahshahanipour, M., and Ensafi, A. A. (2016) A simple and sensitive label-free fluorescence sensing of heparin based on Cdte quantum dots, Luminescence 31, 958-964.

108. Qu, F., Xia, W., Xia, L., You, J., and Han, W. (2019) A ratiometric detection of heparin with high sensitivity based on aggregation-enhanced emission of gold nanoclusters triggered by silicon nanoparticles, Talanta 193, 37-43.

109. Qi, Y., He, J., Xiu, F.-R., Yu, X., Li, Y., Lu, Y., Gao, X., Song, Z., and Li, B. (2019) A facile chemiluminescence sensing for ultrasensitive detection of heparin using charge effect of positively-charged AuNPs, Spectroc. Acta A 216, 310318.

110. Wang, R., Wang, X., and Sun, Y. (2017) Aminophenol-based carbon dots with dual wavelength fluorescence emission for determination of heparin, Microchim. Acta 184, 187-193.

111. Xu, J., Takai, A., and Takeuchi, M. (2016) Red-Green-Blue Trichromophoric Nanoparticles with Dual Fluorescence Resonance Energy Transfer: Highly Sensitive Fluorogenic Response Toward Polyanions, Chem. Eur. J. 22, 1301413018.

112. Ding, S.-N., Li, C.-M., and Bao, N. (2015) Off-on phosphorescence assay of heparin via gold nanoclusters modulated with protamine, Biosens. Bioelectron. 64, 333-337.

113. Aparna, R. S., Anjali Devi, J. S., Anjana, R. R., Nebu, J., and George, S. (2019) Reversible fluorescence modulation of BSA stabilised copper nanoclusters for the selective detection of protamine and heparin, Analyst 144, 1799-1808.

114. Liu, H., Song, P., Wei, R., Li, K., and Tong, A. (2014) A facile, sensitive and selective fluorescent probe for heparin based on aggregation-induced emission, Talanta 118, 348-352.

115. Gong, W., Wang, S., Wei, Y., Ding, L., and Fang, Y. (2017) A pyrene-based fluorescent sensor for ratiometric detection of heparin and its complex with heparin for reversed ratiometric detection of protamine in aqueous solution, Spectroc. Acta A 170, 198-205.

116. Cao, Y., Shi, S., Wang, L., Yao, J., and Yao, T. (2014) Ultrasensitive fluorescence detection of heparin based on quantum dots and a functional ruthenium polypyridyl complex, Biosens. Bioelectron. 55, 174-179. 
117. Bamrungsap, S., Cherngsuwanwong, J., Srisurat, P., Chonirat, J., Sangsing, N., and Wiriyachaiporn, N. (2019) Visual colorimetric sensing system based on the self-assembly of gold nanorods and graphene oxide for heparin detection using a polycationic polymer as a molecular probe, Anal. Methods 11, 1387-1392.

118. Cheng, Q., He, Y., Ge, Y., Zhou, J., and Song, G. (2018) Ultrasensitive detection of heparin by exploiting the silver nanoparticle-enhanced fluorescence of graphitic carbon nitride (g-C3N4) quantum dots, Microchim. Acta 185, 332.

119. Li, Y., Sun, H., Shi, F., Cai, N., Lu, L., and Su, X. (2015) Multi-positively charged dendrimeric nanoparticles induced fluorescence quenching of graphene quantum dots for heparin and chondroitin sulfate detection, Biosens. Bioelectron. 74, 284-290.

120. Liu, J., Liu, G., Liu, W., and Wang, Y. (2015) Turn-on fluorescence sensor for the detection of heparin based on rhodamine B-modified polyethyleneimine-graphene oxide complex, Biosens. Bioelectron. 64, 300-305.

121. Yan, D., He, Y., Ge, Y., and Song, G. (2017) Fluorescence "turn on-off" detection of heparin and heparinase I based on the near-infrared emission polyethyleneimine capped Ag2S quantum dots, Sensors Actuators B: Chem. 240, 863869.

122. Liang, S.-S., Deng, X., Fan, Y.-Y., Li, J., Wang, M., and Zhang, Z.-Q. (2018) A ratiometric fluorometric heparin assay based on the use of CdTe and polyethyleneimine-coated carbon quantum dots, Microchim. Acta 185, 519.

123. Tian, L., Zhao, H., Zhao, Z., Zhai, J., and Zhang, Z. (2019) A facile voltammetric method for detection of heparin in plasma based on the polyethylenimine modified electrode, Anal. Methods 11, 1324-1330.

124. Faham, R., Samadi, A., and Abolhasani, J. (2017) CTAB-Capped Gold Nanoparticles as a New Probe for Spectrophotometric Determination of Heparin, J. Appl. Spectrosc. 84, 425-430.

125. De Groot, A. S., and Scott, D. W. (2007) Immunogenicity of protein therapeutics, Trends Immunol. 28, $482-490$.

126. Nejadnik, M. R., Randolph, T. W., Volkin, D. B., Schöneich, C., Carpenter, J. F., Crommelin, D. J. A., and Jiskoot, W. (2018) Postproduction Handling and Administration of Protein Pharmaceuticals and Potential Instability Issues, $J$. Pharm. Sci. 107, 2013-2019.

127. Gouin-Thibault, I., Pautas, E., and Siguret, V. (2005) Safety Profile of Different Low-Molecular Weight Heparins Used at Therapeutic Dose, Drug Saf. 28, 333-349.

128. Guervil, D. J., Rosenberg, A. F., Winterstein, A. G., Harris, N. S., Johns, T. E., and Zumberg, M. S. (2011) Activated partial thromboplastin time versus antifactor Xa heparin assay in monitoring unfractionated heparin by continuous intravenous infusion, Ann. Pharmacother. 45, 861-868.

129. Guidance for Industry Heparin for Drug and Medical Device Use: Monitoring Crude Heparin for Quality, U.S. fda.gov. https://www.fda.gov/regulatory-information/search-fda-guidance-documents/heparin-drug-and-medical-device-usemonitoring-crude-heparin-quality, (accessed November, 2019).

130. Canal, C., Laugustin, A., Kohl, A., and Rabot, O. (2016) Portable multiwavelength laser diode source for handheld photoacoustic devices, Proc. SPIE, 9887. 